\title{
استخدام معلمي معهد تعليم اللغة العربية بالجامعة الإسلامية بالمدينة المنورة لملف الإنجاز في تقويم الأداء اللغويّ المعاليه
}

\section{دراسة وصفية تحليلية}

The teachers' use of portfolio in the evaluation of linguistic performance in the Institute of Arabic Language Teaching, Islamic University of Al Madinah AI

Munawwara.

An analytical descriptive study

Prepared by: Dr. Abu Bakr Abdalla Ali Shoaib.

Associate Professor of Curriculum Design, Teaching Methods and Teaching Arabic Language to Non-Native Speakers.

Institution: Institute of Arabic Language Teaching, Islamic University of Al Madinah Al Munawwara

$$
\text { إعداد د/ أبوبكر عبد الله علي شعيب }
$$

أستاذ المناهج وطرق التدريس وتعليم اللغة العربية للناطقين بلغات أخرى المشارك. جهة العمل: معهد تعليم اللغة العربية بالجامعة الإسلامية بالمدينة المنورة 


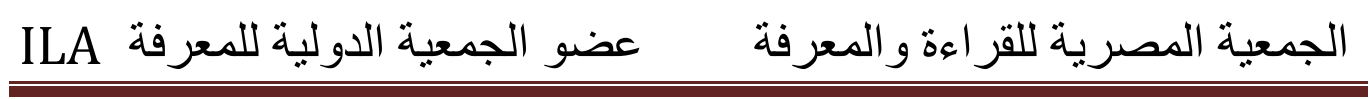




\section{ILA الجمعية المصرية للقر اءة والمعرفة عضو الجمعية الدولية للمعرفة}

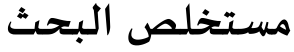

هدف البحث إلى تعرف استخدام معلمي اللغة العربية بمعهد تعليم اللغة العربية بالجامعة الإسلامية بالمدينة المنورة لملف الإنجاز (portfolio) في تقويم الأداء اللغوي لمتعلمي اللغة العربية الناطقين بلغات أخرى، وذلك من خلال بيان استخدام

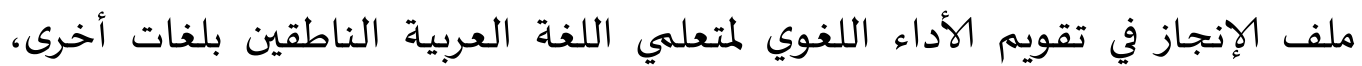
وتعرّف استخدام معلمي اللغة العربية لملف الإنجاز في تقويم الأداء اللغوي لمتعلمي اللغة

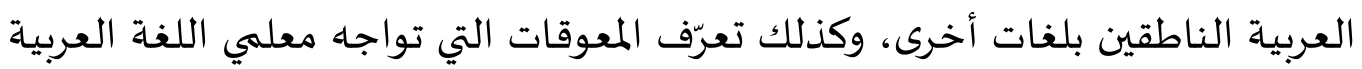
في معهد تعليم اللغة العربية بالجامعة الإسلامية بالمدينة المنورة لاستخدام ملف الإنجاز تقويم الأداء اللغوي.

استخدم الباحث المنهج الوصفي التحليل. وكانت نتائج البحث كالآتي: 1- معظم عبارات محور أهمية استخدام معلمي اللغة العربية للناطقين بغيرها ملف الإنجاز في تقويم الأداء اللغوي كانت بين كبيرة وكبيرة جدا.

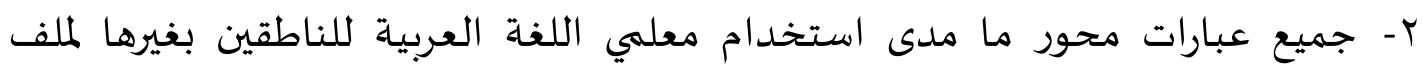

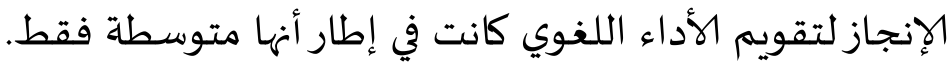
r- جميع عبارات محور المعوقات التي تحول دون استخدام معلمي معهد تعليم اللغة العربية لملف الإنجاز لتقويم الأداء اللغوي كانت بين كبيرة وكبيرة جدا؛ أي أن المعوقات

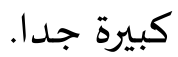
وعلى ضوء هذه النتائج خلص البحث إلى عدة توصيات ومقترحات. الكلمــات المفتاحيــة: معلمــو معهـــ تعلـيم اللغــة العربيـة، ملـف الإنجــاز، تقــويمه، الأداء اللغويّ. 


\section{الجمعية المصرية للقراعة والمعرفة عضو الجمعية الدولية للمعرفة ILA}

\section{ABSTRACT}

The aim of the research is to identify the use of portfolio by Arabic language teachers of the Institute of Arabic Language Education in the Islamic university of Madina, in the assessment of language performance of the non-Arabic speaking learners of the Arabic language, and to also identify the challenges and obstacles faced by the Arabic language teachers of the Institute of Arabic Language Education in the Islamic university of Madina in the use of the portfolio for assessing language performance and progress

The researcher adopted the descriptive analytical method and the outcome was as follows:

i. Most expressions centering the importance of using the portfolio by the Arabic language teachers to assess language performance of the non- Arabic speaking learners of the Arabic language ranged between great and greater.

ii. All expressions on the point of : to what extent is the use portfolio by the Arabic language teachers to assess language performance of the non-Arabic speaking learners of the Arabic language. The response was average only.

iii. All expressions on the point of the obstacles and challenges facing the use of the portfolio by the Arabic language teachers of the Institute of Arabic Language Education to assess the language progress and performance was between great and greater.

And in the light of these results, the research concluded on some recommendations and suggestions

Keywords: teachers of the Institute of Teaching Arabic Language, portfolio, evaluation . linguistic performance. 


\section{ILA الجمعية المصرية للقر اءة والمعرفة عضو الجمعية الدولية للمعرفة}

الاحساس بمشكلة البحث

كثير من الدراسات أكدت أن ملف الإنجاز له دور كبير في تشجيع الطلاب على

التقويم الذاتي لأعمالهم مثل دراسة فلمبان (اس؟اءه) التي أظهرت أهمية استخدام معلمات اللغة العربية ملف الإنجاز في تقويم أداء الطالبات بدرجة عالية، ودراسة

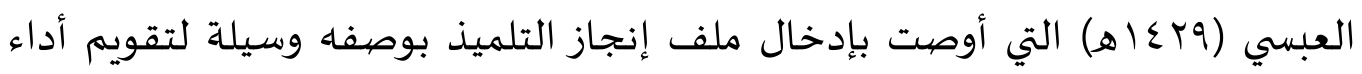
التلاميذ، والعمل من خلال الملف على تقديم معلومات حول تقدم التلميذ نحو تحقيق

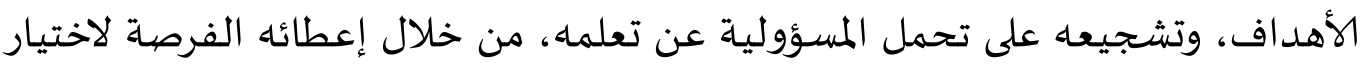

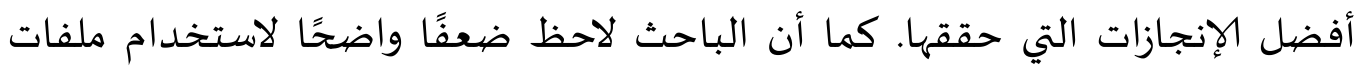

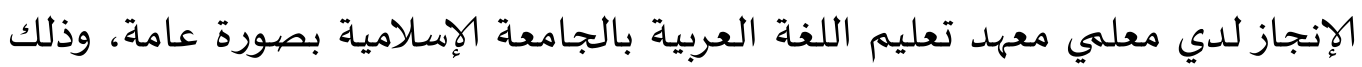
من خلال القاء ببعض المعلمين وسؤالهم.

\section{مشكلة البحث}

اختار الباحث أن يبحث في استخدام معلمي معهد تعليم اللغة العربية بالجامعة الإسلامية بالمدينة المنورة لملف الإنجاز في تقويم الأداء اللغويّ لدى طاحئ لاب المعهد. أسئلة البحث ويتطلب البحث الإجابة عن السؤال الرئيس وما يتفرع عنه من أسئلة. السؤال الرئيسي ما واقع استخدام ملف الإنجاز لدى معلمي اللغة العربية في معهد تعليم اللغة

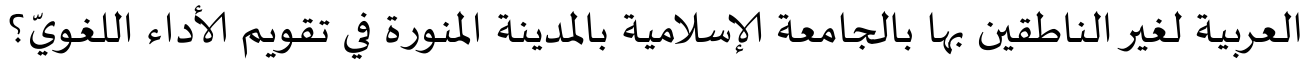
ويتفرع عن هذا السؤال الأسئلة الآتية: 


\section{الجمعية المصرية للقر اءة و المعرفة عضو الجمعية الدولية للمعرفة}

ا. ما أهمية استخدام ملف الإنجاز لدى معلمي معهد تعليم اللغة العربية لغير الناطقين بها بالجامعة الإسلامية بالمدينة المنورة في تقويم الأداء اللغوي لمتعلمي اللغة العربية

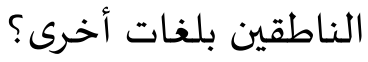

r. ما مدى استخدام معلمي معهد تعليم اللغة العربية لغير الناطقين بها بالجامعة

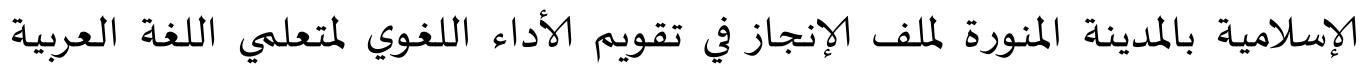
الناطقين بلغات أخرى؟ - المبنه r. ما المعوقات التي تواجاء معلمي معهد تعليم اللغة العربية لغير الناطقين بها بالجامعة

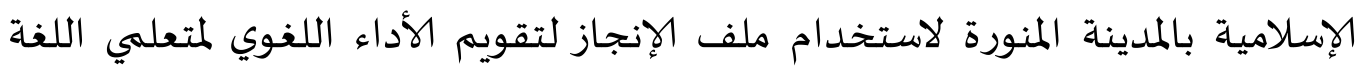
العربية الناطقين بلغات أخرى؟ بالمدينه أهداف البحث هدف البحث إلى القيام بالآتي: ا. بيان أهمية استخدام معلمي معهد تعليم اللغة العربية لغير الناطقين بها بالجامعة الإسلامية بالمدينة المنورة لملف الإنجاز في تقويم الأداء اللغوي لمتعلمي اللغة العربية

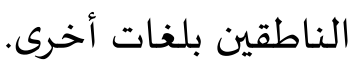

r. تعرّف استخدام معلمي معهد تعليم اللغة العبية لغير الناطقين بها بالجامعة

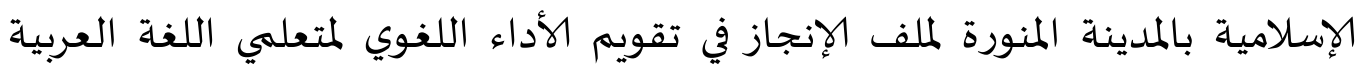

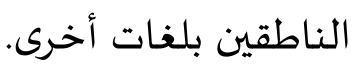

r. تعرّف المعوقات التي تواجه معلمي معهد تعليم اللغة العربية لغير الناطقين بها

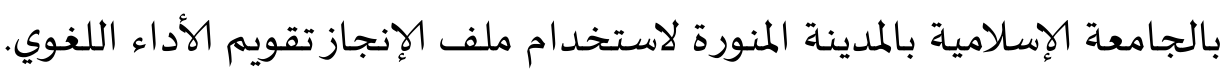




\section{ILA الجمعية المصرية للقر اءة والمعرفة عضو الجمعية الدولية للمعرفة}

\section{أهمية البحث}

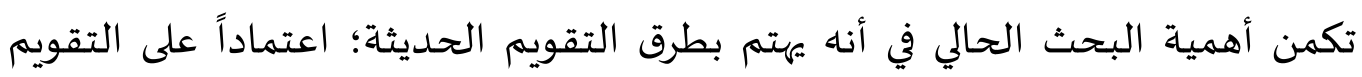
البديل الذي يعد ملف الإنجاز أحد أساليبه.

وتتضح أهمية البحث الحالي في الإفادة منه في جوانب عدة تتمثل في التالي:

1. يكشف للمسئولين والمختصين في معهد تعليم اللغة العربية بالجامعة الإسلامية بالمدينة المنورة واقع استخدام أعضاء هيئة التدريس ومعلهي المعهد ملف الإنجاز في تقويم الأداء اللغوي لدى الطلاب.

r. يساعد أعضاء هيئة التدريس والمعلمين على توجيه ممارستهم للتقويم بملف الإنجاز وتطويره؛ لرفع مستوى التعلم اللغوي لدى الطلاب.

r. قد تفتح نتائج البحث للباحثين في المجال لإجراء دراسات استكمالاً لهذا الموضوع من

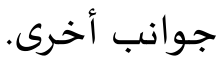

ع. يقدم الفائدة للقائمين على إعداد معلمي اللغة العربية للناطقين بلغات أخرى في تحسين البرامج والمقررات في مجال التقويم، التي تقدم لطلاب معاهد تعليم اللغة الفية العربية لغير الناطقين بها في المملكة العربية السعودية.

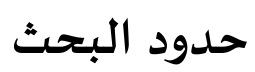

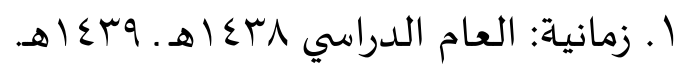

r. مكانية: معهد تعليم اللغة العربية لغير الناطقين بها بالجامعة الإسلامية بالمدينة المنورة.

r. موضوعية: تعرّف واقع استخدام ملفات الانجاز لدى معلمي معهد تعليم اللغة العربية لغير الناطقين بها بالجامعة الإسلامية بالمدينة المنورة لتقويم الأداء اللغوي. 


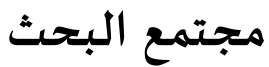

أعضاء هيئة التدريس ومن في حكمهم، ومعلمو معهد تعليم اللغة العربية لغير

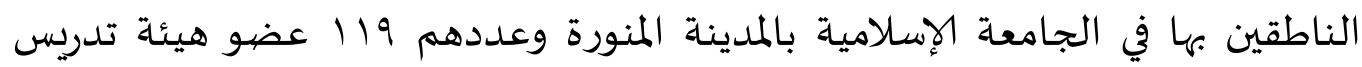

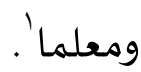
عينة البحث

عينة عشوائية من أعضاء هيئة التدريس ومن في حكمهم، والمعلمين في معهد تعليم اللغة العربية لغير الناطقين بها بالجامعة الإسلامية بالمدينة المنورة وكان عددهم ولينه منهرج البحث

اتبع الباحث المنهج الوصفي " التحليلي " في البحث، وفي جمع المعلومات

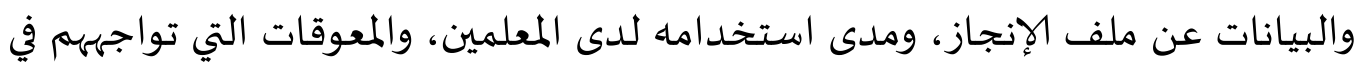
استخداماه. أدوات البحث

استخدم الباحث الاستبانة؛ باعتبارها أنسب الأدوات من وجهة نظره، حيث صمّمم استبانة لأعضاء هيئة التدريس ومن في حكمهه، والمعلمين بالمعهد. مصبطلحات البحث ملف الإنججاز portfolio

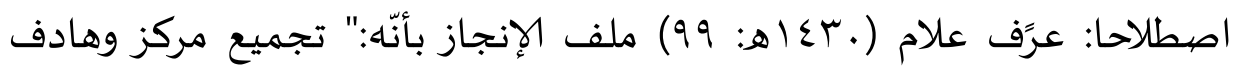
لأعمال الطالب يبيّن جهوده، وتقدماه، وتحصيله في مجال أو مجالات دراسـة معينة.

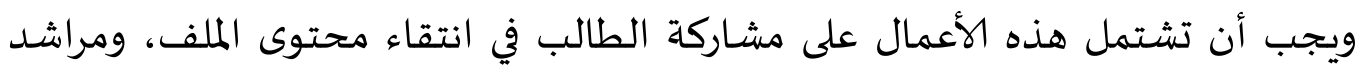




\section{الجمعية المصرية للقر اعة والمعرفة عضو الجمعية الدولية للمعرفة المي}

هذا الانتقاء، ومحكات الحكم على نوعية الأعمال وأدلة على انعكاسات الطالب أو تأملاته الذاتية على هذه الأعمال ".

إجرائيًا: تجميع مركز وهادف لأعمال الطالب في معهد تعليم اللغة العربية لغير الناطقين بها بالجامعة الإسلامية بالمدينة المنورة؛ يبيّن جهوده، وتقدماه، وتحصيله في مئي عناصر اللغة العربية ومهاراتها.

Linguistic Performance الأداء اللغوي

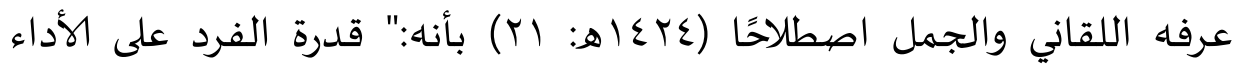
اللغوي الصحيح قراءةً وكتابةً وتحدثاً وتعبيراً." إجرائيًا: قدرة طلاب معهد تعليم اللغة العربية بالجامعاة الإسلامياة بالمدينة المنورة على الأداء اللغوي الصحيح لعناصر اللغة العربية ومهارها بصورة صحيحة.

$$
\text { إجراءات البحث: }
$$

$$
\text { للإجابة عن أسئلة البحث اتبع الباحث الإجراءات الآتية: }
$$

ا. الاطلاع على الكتابات النظرية، والدراسات السابقة التي تناولت ملف الإنجاز في التقويم التربوي واللغوي.

r. إعداد استبانة تتألف من أهمية ملف الإنجاز لمتعلمي اللغة العربية الناطقين بلغات أخرى، واستخدامه بالنسبة لمعلمي معهد تعليم اللغة العبية بالجامعة الإسلامية بالمدينة المنورة والصعوبات التي تواجههم، وتحكيمها لدى متخصصين في علم اللغة بهات التطبيقي وعلم اللغة والمناهج وطرائق تدريس اللغة العربية. r. إعداد الاستبانة في صورتها النهائية بعد الأخذ بآراء المحكمين. ع. توزيع الاستبانة على عينة البحث من أعضاء هيئة التدريس والمعلمين في معهد تعليم اللغة العربية لغير الناطقين بها بالجامعة الإسلامية بالمدينة المنورة. 


\section{ILA الجمعية المصرية للقر اءة والمعرفة عضو الجمعية الدولية للمعرفة}

0. - رصد النتائج وتحليلها، وتفسيرها. 7. تقديم التوصيات، والمقترحات على ضوء النتائج. الإطار النظري ملف الإنجاز portfolios عرّفه علام (.بـا هـ: 9 9) ملف الإنجاز بأنّه:" تجميع مركز وهادف لأعمال الطالب يبيّن

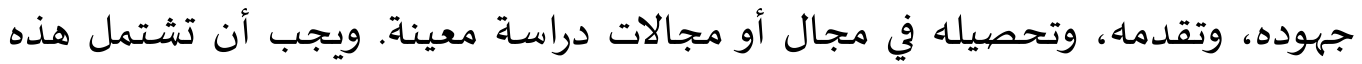

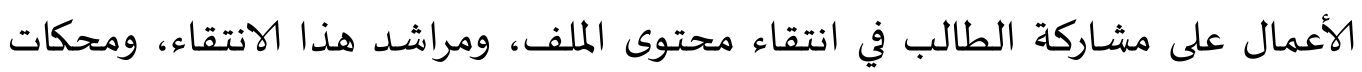

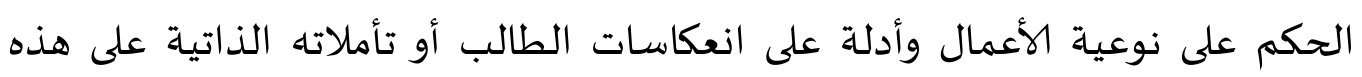
الأعمال".

\section{مفهوم ملف الإنجاز portfolio}

مفهوم ملف الانجاز يعد من المفاهيم التي تثير كثيراً من الإباك لدى المربين؛

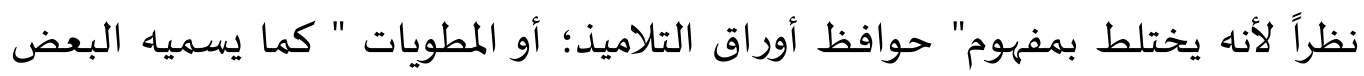

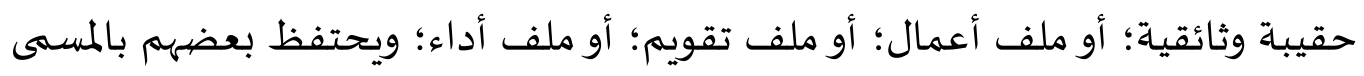

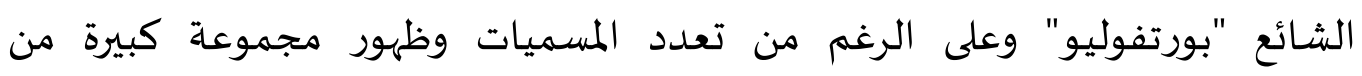

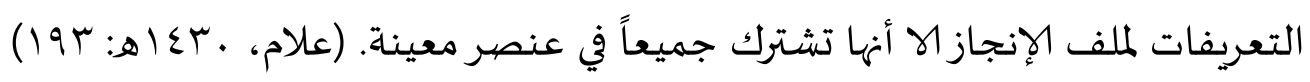
ومن هذه التعريفات تعريف جومز (...... ، Gomez) الذي أشارت إليه البركاني

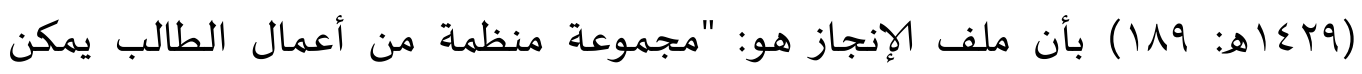

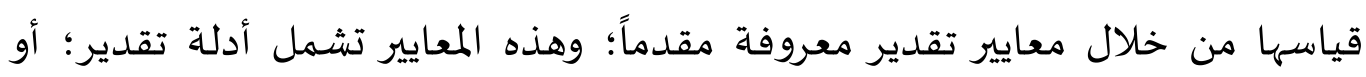

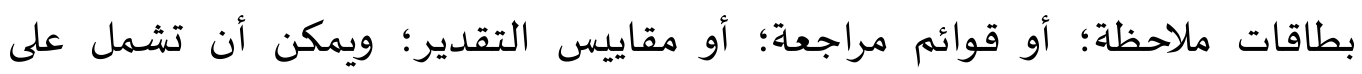
تقييمات مبنية على الأداء؛ أو تقارير معملية؛ أو تقارير بحثية". 


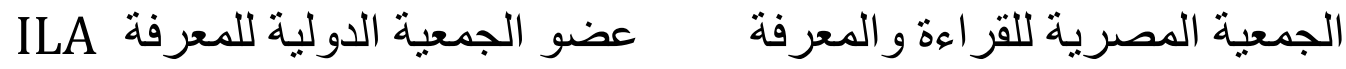

\section{أهداف ملف الإنجاز}

الهدف من ملف الإنجاز هو إبراز نقاط القوة لدى الطالب؛ وتعزيزها؛ وتطور

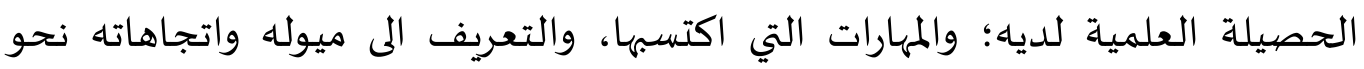
المادة الدراسية من خلال اختياره للموضوع؛ واستخراجه للمفاهيم الرئيسية؛ والفرعية والمانية

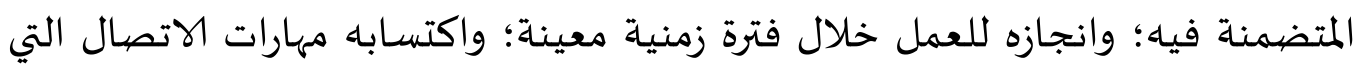
يمكنه عن طريقها التعامل مع الاخرين واقناعهم؛ ومقدرته على الاستماع؛ والمناقشة الماتة البناءة؛ وكذلك مدى تقدمه نحو

الأهداف الخاصة بالمادة التعليمية وذلك عن طريق الاختيارات التي يتضمنها الملف. (أبو

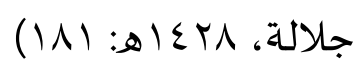
من خصائص ملف الإنجاز من أبرز خصائص ملف الإنجاز ما يلي: • حافظة؛ أو سجل؛ أو ملف؛ أو حقيبة.

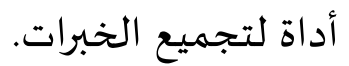
• حافظة تضم أفضل الأعمال المختارة. يعرض النمو؛ والتطور موثوقاً بالأدلة؛ والبراهين. ه أداة للتقويم الذاتي؛ أو لتقويم الآخرين عن الفرد. هركز على مجال معين؛ أو مجالات مختلفة. يعرض المنجزات الإبداعية؛ والثقافية. • أداة قابلة للتجديد؛ باستبدال الأعمال السابقة بالحديثة. يمتاز بالشمول لجميع جوانب النمو؛ ومجالاته. 


\section{الجمعية المصرية للقر اعة و المعرفة عضو الجمعية الدولية للمعرفة}

يراعي الفروق الفردياة بين الطلاب.

تساعد النتائج التي نحصل علهها من الملفات في تطوير المناهج؛ وطرق التدريس؛

والأنظمة الإدارية.

تطبيق المعرفة؛ حيث تتطلب من التلاميذ تطبيق معرفتهم؛ ومهاراتهم.

ينهي التفكير الناقد لدى التلميذ من خلال تقويم أدائه؛ ونقده لأعماله.

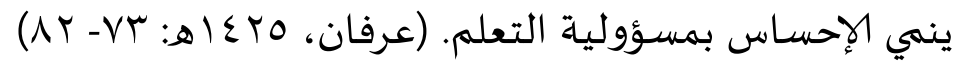

محتويات ملف الإنجاز

يختلف حجم ملف إنجاز التلميذ من فصل الى فصل؛ ومن مادة دراسية الى

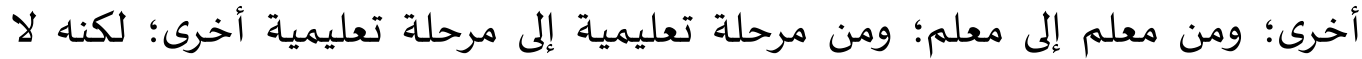

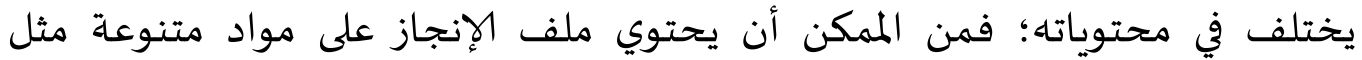
(ملاحظات المعلم؛ ردود الأفعال للتلميذ؛ وقائمة قراءاته؛ وعينات من صفحات الجرائد والمجلات؛ وملخصات مكتوبة، وأشرطة تسجيل للقراءة الشفهية). ويلاحظ أن محتويات الملف تكون من اختيار الطالب نفسـ؛ ويمكن أن يشارك المعلم في الاختيار.

ويقترح أن يحتوي ملف الإنجاز على كثير من الأنشطة؛ والجهود؛ والأعمال التي

قام بها الطالب متعلم اللغة العربية للناطقين بغيرها من صور وأوراق عمل، وأنشطة إثرائية وتسجيلات صوتية، وقوائم المصادر التي اطلع عليها الطالب، والمواد التي

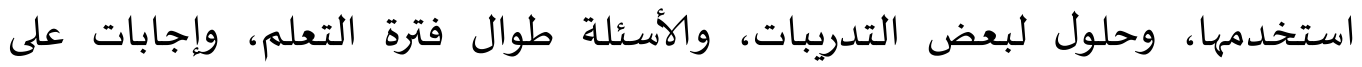

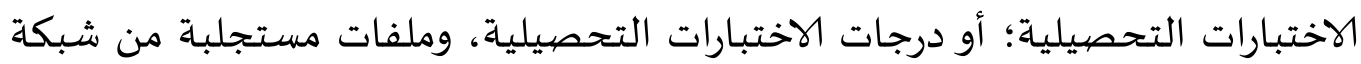
الانترنت ومعايير.

ويتضح مما سبق أن محتويات ملف إنجاز الطالب على الرغم من تنوعها إلا أن جميعها تدور في مجال واحد وهو أن يختار الطالب بنفسه محتويات الملف؛ وكيفية 


\section{الجمعية المصرية للقر اءة والمعرفة عضو الجمعية الدولية للمعرفة}

تنظيمه؛ تحت إشـراف وتوجياء المعلم؛ حيث إن هذا ينمي لديها مهارات التنظيم الذاتي؛ والإبداع.

\section{تقويم ملف الإنجاز:}

من الصعب تقويم ملف إنجاز الطالب بدرجة عالية من الثبات بدون وجود

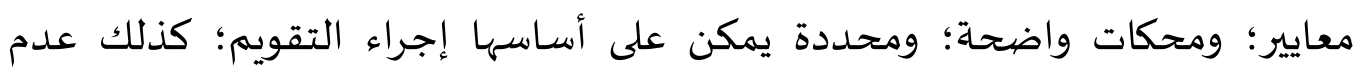

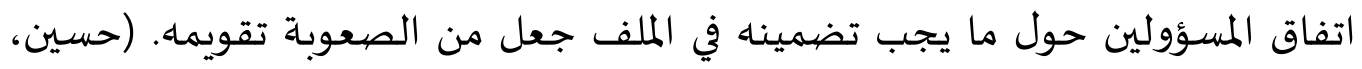
(7T: (7)

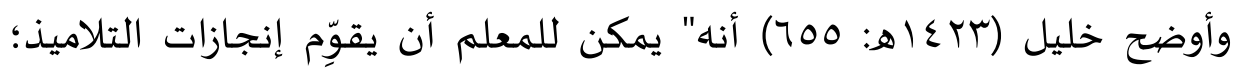
فدائما ما يقارن عمل التلميذ بعمله السابق؛ حيث يجب أن يشير هذا التقويم الى تقدم التهات

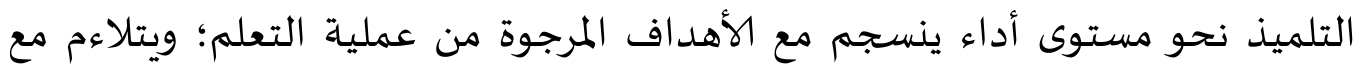

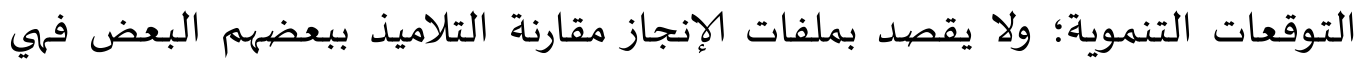
تستخدم لتوثيق التقدم الفردي للتلميذ عبر الزمن". وهناك طرقاً متعددة لتقويم ملف إنجاز الطالب؛ وتقدير درجاته وفقاً للغرض من هذا الملف؛ واستخدامه؛ وعلى الرغم من اختلاف الطرق إلا أهها تؤكد أهمية

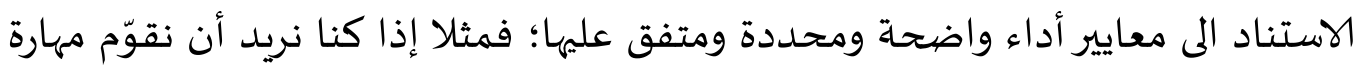

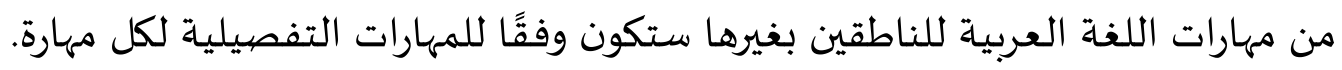
تنوعت الدراسات التي تناولت التقويم بملف الإنجاز، وقد شملت هذه الدراسات موضوعات متعددة، كما طبقت على تخصصات عدة، وفي مراحل دراسية

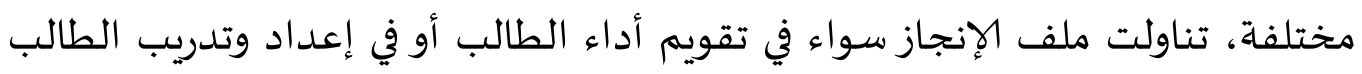
المعلم.

من هذه الدراسـات دراسة شين Chen (Y . . (Y) هدفت إلى التحقق من فاعلية استخدام

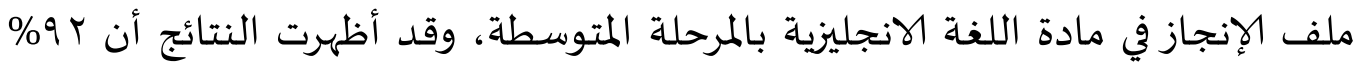




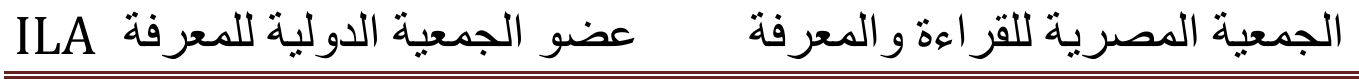

من التلاميذ أكدوا على أن المعلمين باستخدامهم ملف الإنجاز في التقويم أصبحوا أكثر تفاعلا مع التلاميذ، وأكثر توضيحا لأهداف.

وأجرت خلود مراد (rY\& (هـ) في البحرين دراسة حول أساليب التقويم لدى

معلمي ومعلمات الحلقة الأولى من التعليم الابتدائي في ظل نظام التقويم التربوي،

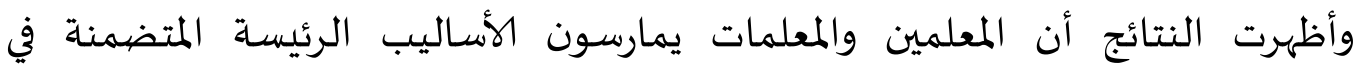
الاستبانة وهي (الاختبارات بأنواعها، الملاحظ، وملف إنجاز التلميذ) بدرجة مقبولة، مع وجود فروق ذات دلالة إحصائية تعرى للخبرة، ويقوم 07\% من المعلمين بتضمين نتائج الاختبارات في ملف إنجاز التلميذ.

وهدفت دراسـة الهواري (بr عاهـ) إلى تعرّف أثر كل من طريقة التدريس ونمط التقويم على مستوى الأداء اللغوي الشفهي لتلاميذ الصف الخامس الابتدائي. وتوصلت نتائج الدراسة إلى وجود فروق دالة إحصائية بين التلاميذ في مستوى مهارات الأداء

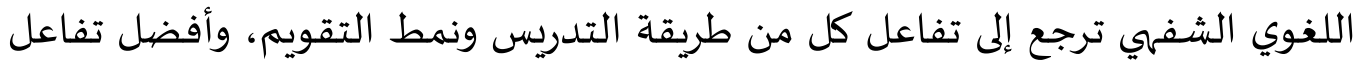
هو بين طريقة فرق الألعاب في التدريس، وملف الإنجاز في التقويه. وأجرت حياة الآغا (Y0 أه) دراسة هدفت إلى معرفة أثر استخدام ملفات

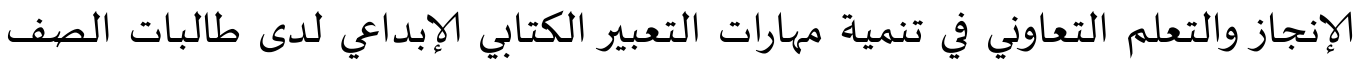
العاشر بفلسطين، وقد أظهرت النتائج تفوق طالبات مجموعة ملف الإنجاز (التجريبية الأولى) ومجموعة التعلم التعاوني (التجريبية الثانية) على طالبات مجموعـة الاعتيادية،

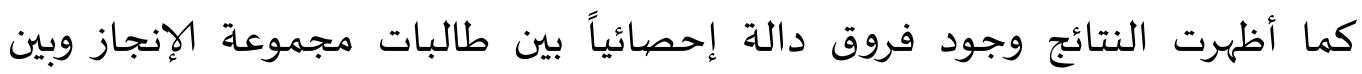

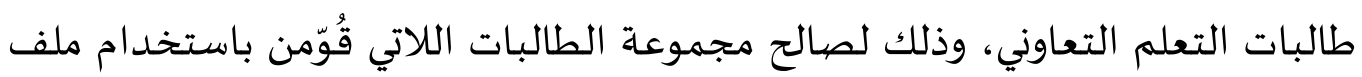
الإنجاز.

وفي الكويت قامت بدرية المفرج وأخريات ( تعرّف واقع تطبيق التقويم باستخدام الملف الإنجازي لتلميذ المرحلة الابتدائية، وأسفرت النتائج عن موافقة معظم المعلمين والموجهين بدرجة متوسطة على أهمية 


\section{الجمعية المصرية للقر اعة والمعرفة عضو الجمعية الدولية للمعرفة المي}

التقويم بالملف الإنجازي، وعدم تأييد معظم المعلمين بنسبة (1\%V7) ومعظم الموجهين بنسبة (م٪) لتطبيق الملف الإنجازي؛ مما يدل على خلل في آلية التطبيق.

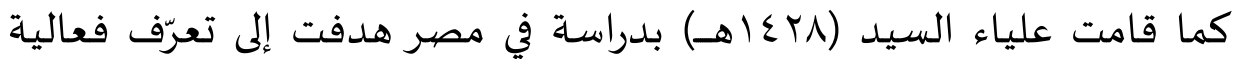
التقويم بملف التعلم في تنمية التحصيل، والتفكير الابتكاري، وخفض قلق الامتحانات لدى تلاميذ المرحلة الابتدائية في مادة العلوم، وأظهرت النتائج تفوق المجموعاة التجريبية في كل من التحصيل، والتفكير الابتكاري، وساعد استخدام ملف التعلم في خفض قلق الامتحانات لديهم.

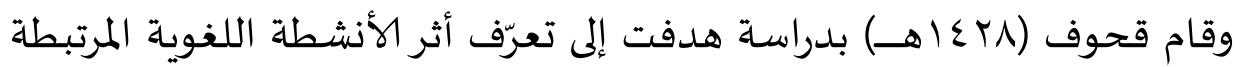
بملفات الإنجاز في تنمياة بعض مهارات الفهم القرائي، وبعض مهارات الكتابة لدى تلاميذ

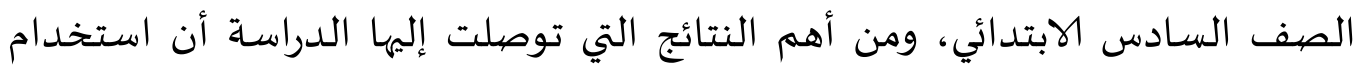

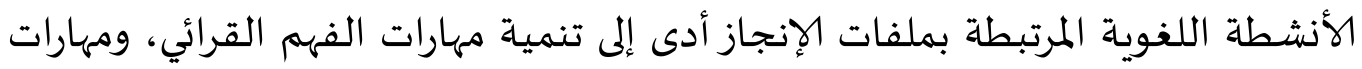

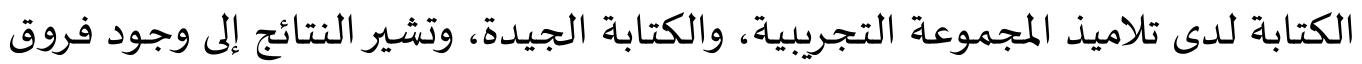

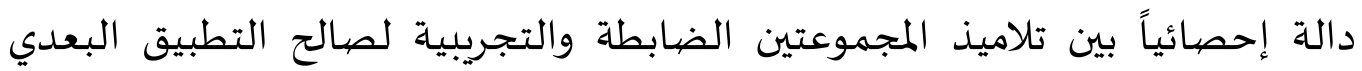
لتلاميذ المجموعاة التجريبية.

وأجرت فلمبان (ابrع اهـ) دراسة هدفت إلى تعرّف واقع استخدام معلمات اللغة العربية ملف الإنجاز في تقويم تلميذات الصف السادس الابتدائي بمدينة مكة المكرمة، وأظهرت النتائج أن درجة استخدام معلمات اللغة العربية ملف الإنجاز في تقويم تلميذات الصف السـادس الابتدائي بمدينة مكة المكرمة جاءت متوسطة، وأن صعوبات استخدامهن ملف الإنجاز كانت بدرجة عالية.

بعد الاطلاع على هذه الدراسات نجد الباحث قد استفاد منها في الآتي: بلورة موضوع البحث لدياه والإفادة من استخدام المنهج المناسب، وكذلك الإفادة من الإطار النظري. ويختلف هذا البحث عنها في أهها تتقصي واقع استخدام ملف

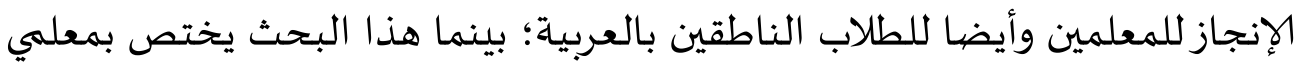




\section{الجمعية المصرية للقر اعة والمعرفة عضو الجمعية الدولية للمعرفة المي}

اللغة العربية الذين يدرّسون طلابا غير ناطقين بها، ويعملون في مؤسسـات تعليمياة تهتم بهذا الجانب.

\section{إعداد أداة البحث}

الأداة التي استخدمت في البحث هي: استبانة واقع استخدام معلمي معهد تعليم

اللغة العربية بالجامعة الإسلامية بالمدينة المنورة لملف الإنجاز في تقويم الأداء اللغويّ.

$$
\text { تهدف الاستبانة من إعداد الاستبانة }
$$

ا ـ بيان أهمية استخدام ملف الإنجاز لمعلمي معهد تعليم اللغة العربية لغير الناطقين بها

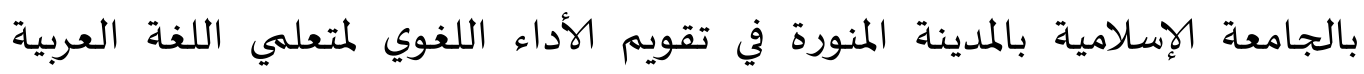

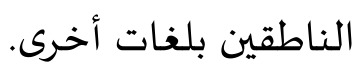
r. تعرّف مدى استخدام معلمي معهد تعليم اللغة العربية لغير الناطقين بها بالجامعة

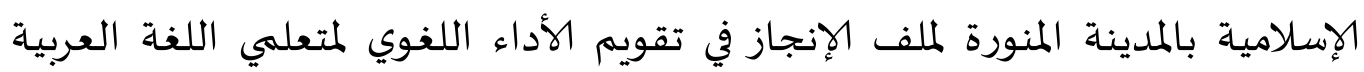

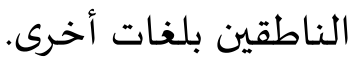

r. تعرّف المعوقات التي تواجه معلمي معهد تعليم اللغة العربية لغير الناطقين بها

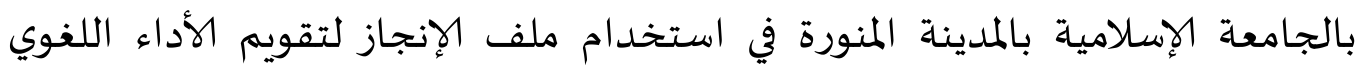

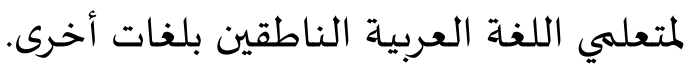

\section{مصيادر إعداد الاستبانة}

تمثلت في المراجع العلمية ذات الصلة والدراسات السابقة التي تناولت

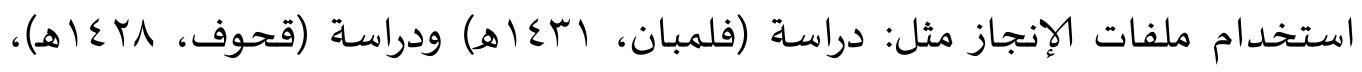

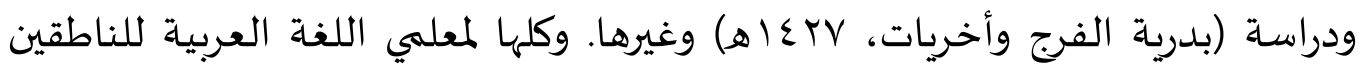




\section{ILA الجمعية المصرية للقر اءة والمعرفة عضو الجمعية الدولية للمعرفة}

بها، ولم يتحصل الباحث على دراسة لاستخدام ملف الإنجاز لمعلمي اللغة العببية للناطقين بغيرها. إعداد الاستبانة في صورتها الأولية: تضمنت الاستبانة في صورتها الأولية ما يأتي: - مقدمة توضح للمحكمين الهدف من إعداد الاستبانة. - - المطلوب من المحكمين إبداء الرأي فياء.

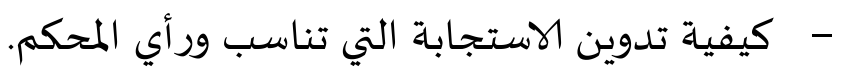
- التعريف الإجرائي لملف الإنجاز، والتعريف الإجرائي للأداء اللغوي. ولقد اشتملت الاستبانة في صورتها الأولية على ثلاثة محاور وهي: ا. بيان أهمية استخدام ملف الإنجاز لمعلمي معهد تعليم اللغة العربية بالجامعة

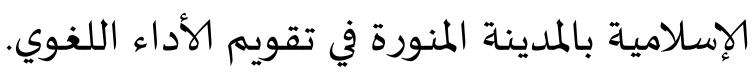

r. تعرّف مدى استخدام معلمي معهد تعليم اللغة العربية بالجامعة الإسلامية بالمدينة المنورة لملف الإنجاز لتقويم الأداء اللغوي لمتعلمي اللغة العربية الناطقين بلغات أخرى. r. تعرّف المعوقات التي تواجه معلمي اللغة العربية في معهد تعليم اللغة العربية

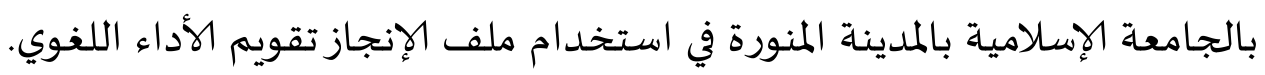
انبثق من المحور الأول ثمان عشرة عبارة فرعياة، ومن المحور الثاني سبع عشرة عبارة فرعية، ومن المحور الثالث أربع عشرة عبارة فرعية. الاستبانة في صورتها الأولية على المحكمين عرضت الاستبانة على مجموعة من المحكمين متخصصين في مجال علم اللغة

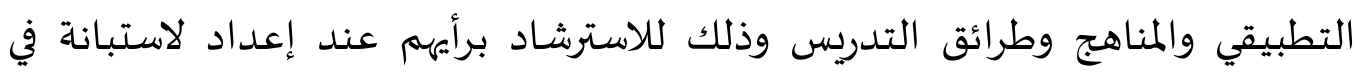
صورتها النهائية وبهدف إجراء التعديلات المناسبة وفق ما يرونه من من حيث ميث ملاءمة 


\section{ILA الجمعية المصرية للقر اءة والمعرفة عضو الجمعية الدولية للمعرفة}

العبارات الفرعية للمحاور، والدقة العلمية للعبارات، وكذلك الدّقة اللغوية لها، كما طلب منهم إضافة ما يروناه مناسبًا من عبارات لم ترد بالاستبانة. والجدول التالي يبين الإحصاءات الوصفية لبيانات المحكين

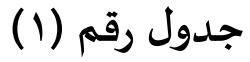

يبين الإحصاء/ت الوصفية لبيانات المحكمين:

\begin{tabular}{|c|c|c|c|}
\hline المعياري & المتوسط الحسبي & عدد & \\
\hline$\ldots$ & 1 & r & جهة العمل \\
\hline 1.488 & 2.88 & 36 & الدرجة العلمية \\
\hline 3.249 & 5.88 & 36 & التخصص العلمي \\
\hline .731 & 1.75 & 36 & سنوات الخبرة \\
\hline
\end{tabular}

الجدول أعلاه يبين للباحث الإحصاءات الوصفية لبيانات المستجيبين وكان حجم العيناة ستة وثلاثون مستبينًا مع عدم وجود قيم مفقودة ونجد أن المتوسط المبان الحسابي لجهاة العمل كانت قيمته (واحد صحيح) انحرافا معياريا قيمتاه . ... وهذا

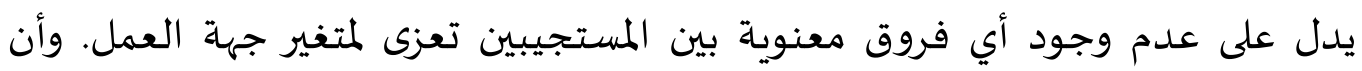

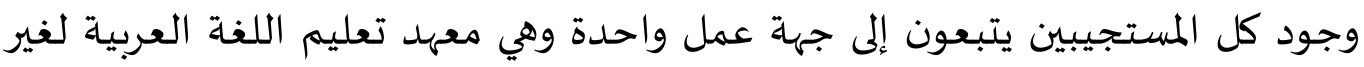
الناطقين بها بالجامعة الإسلامية بالمدينة المنورة.

كما نجد أن المتوسط الحسابي لدرجة المستجيبين العلمياة كانت قيمتاه 19.19 بانحراف معياري قيمته وع.ا مما يدل ذلك على اختلاف المستجيبين في الدرجة العلمية. ونجد أيضا أن المتوسط الحسابي للتخصص العلمي للمستجيبين كانت قيمتاه 0.19 بانحراف معياري قيمته 0r.r مما يدل ذلك على اختلاف المستجيبين في 


\section{ILA الجمعية المصرية للقر اءة والمعرفة عضو الجمعية الدولية للمعرفة}

التخصص العلمي، ويظهر لنا اختلافا طفيفا في متغير سنوات الخبرة حيث كان متوسطه

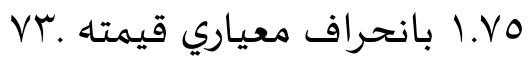

$$
\text { جدول رقم (r) (r) (r) (x) }
$$

يوضيح التكرارات النسب المئوية الدرجة العلمية: الدرجة العلمية للمحكممين

\begin{tabular}{|c|c|c|}
\hline المئوية & العدد & ألعضشاء \\
\hline 27.8 & 10 & مدرس \\
\hline 5.6 & 2 & مسـاعد تـريس \\
\hline 36.1 & 13 & محاضر \\
\hline 16.7 & 6 & أستاذ مسـاعد \\
\hline 8.3 & 3 & أستاذ مشـارك \\
\hline 5.6 & 2 & أستاذ دكتور \\
\hline 100.0 & 36 & المجموع \\
\hline
\end{tabular}

الجدول والشكل أعلاه يبينان أن عدد الأساتذة المستجيبين بدرجة مدرس كان

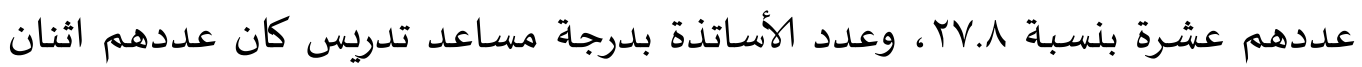

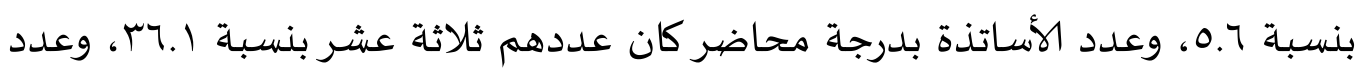

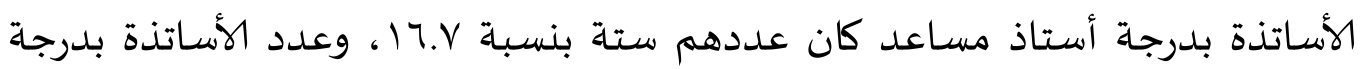

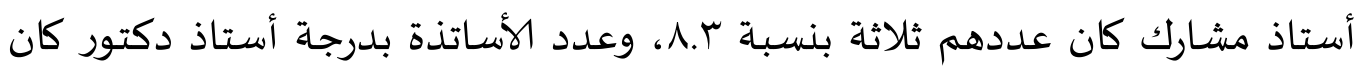

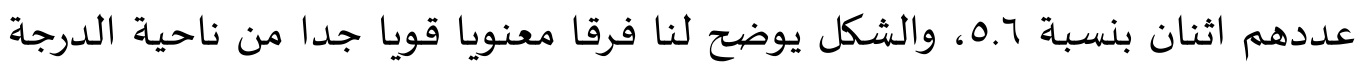
العلمية للمحكمين 
إعداد الصورة الهائية للاستبانة:

بعد إجراء التعديلات التي أشار إليها المحكمون اللغوية والعلمية والتنظيمياة،

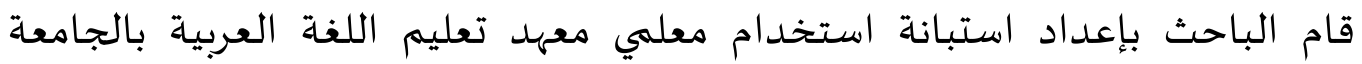
الإسلامية بالمدينة المنورة لملف الإنجاز في تقويم الأداء اللغويّ. انبثق من الماديد المحور الأول

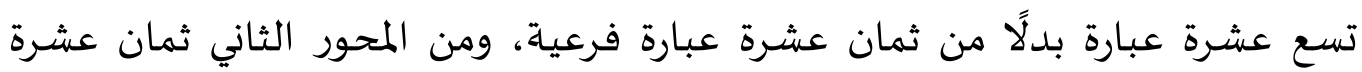

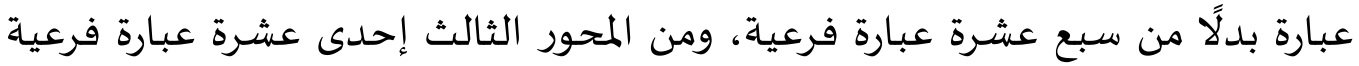

$$
\text { بداًًا من أربع عشرة عبارة فرعية. }
$$

الجدول التالي يجيب عن السؤال الأول الذي نصها: "ما مدى أهمية استخدام

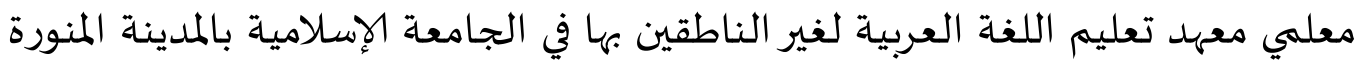

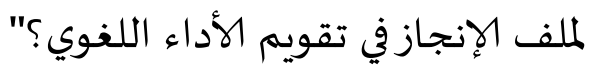

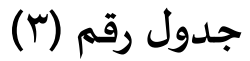

يوضح التكرارات والنسب المئوية والمتوسط العام للبيانات ومتوسط مقياس ليكرت

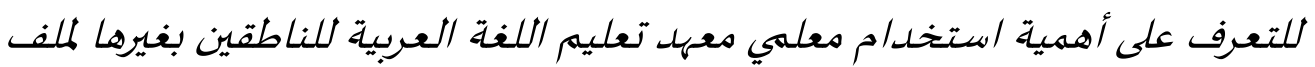

\begin{tabular}{|c|c|c|c|c|c|c|c|c|c|}
\hline \multirow{2}{*}{$\begin{array}{l}3 \\
3 \\
3 \\
3 \\
3 \\
3 \\
3\end{array}$} & \multirow{2}{*}{ 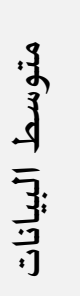 } & \multicolumn{2}{|c|}{ كبيرة جدا } & \multicolumn{2}{|c|}{ كبيرة } & \multicolumn{2}{|c|}{ كبيرة الى حد } & \multirow[t]{2}{*}{ العبـارة } & \multirow[t]{2}{*}{ الاتجاه } \\
\hline & & . ָּ了. & $\frac{\overline{3}}{3}$ & لِّ. & $\frac{\overline{3}}{3}$ & ل. & $\frac{\overline{3}}{2}$ & & \\
\hline 2 & 2.50 & 53.3 & 21 & 33.3 & 12 & 8.3 & 3 & العروبية في المعهد. تحقيق أهداف تعليم اللغة & كبيرة \\
\hline 2 & 2.55 & 6.1 & 22 & 33.3 & 12 & 5.6 & 2 & مهارات اللغة العببية مع مرور الوقت. الطتلاب & كبيرة \\
\hline
\end{tabular}
الإنجاز في تقويم الأداء اللغوي. 


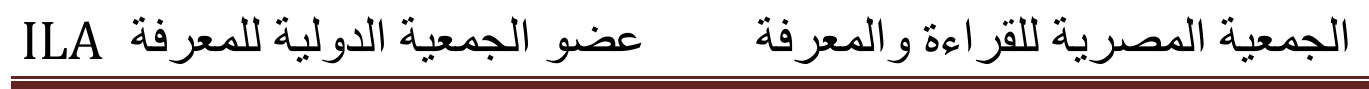

\begin{tabular}{|c|c|c|c|c|c|c|c|c|c|}
\hline 2 & 2.33 & 44.4 & 16 & 44.4 & 16 & 11.4 & 4 & العربيد من الدافعية نحو تعلم اللغة & كبيرة \\
\hline 2 & 2.63 & 66.7 & 24 & 30.6 & 11 & 2.8 & 1 & ينمي القدرة على التعلم الذاتي. & كبيرة \\
\hline 2 & 2.36 & 52.8 & 19 & 30.6 & 11 & 16.7 & 6 & ينمي القدرة على الإبداع اللغوي. & كبيرة \\
\hline 2 & 2.44 & 58.3 & 21 & 27.8 & 10 & 13.9 & 5 & 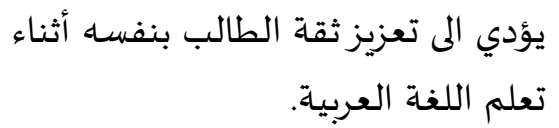 & كبيرة \\
\hline 2 & 2.58 & 33.9 & 23 & 30.6 & 11 & 5.6 & 2 & والأداء اللغوي الجفزادة الطلاب على البحث عن المعرفة & جبيرة \\
\hline 2 & 2.44 & 52.8 & 19 & 38.9 & 14 & 8.3 & 3 & تسريس اللغدة على تطوير طرق وأساليب & جبيرة \\
\hline 2 & 2.44 & 52.8 & 19 & 38.9 & 14 & 8.3 & 3 & 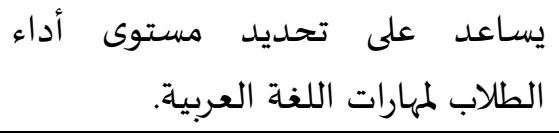 & جبيرة \\
\hline 2 & 2.22 & 47.2 & 17 & 27.8 & 10 & 25.0 & 9 & لدؤدي الى تنمية أساليب التفكير العلمي & كبيرة \\
\hline 2 & 2.41 & 58.3 & 21 & 25.0 & 9 & 16.7 & 6 & الصؤدي الى زيادة تفاعل الطلاب داخل & كبيرة \\
\hline 2 & 2.61 & 66.7 & 24 & 27.8 & 10 & 5.6 & 2 & أثناء تعلم اللغة الطلاب على تحمل المسؤولية & جبيرة \\
\hline 2 & 2.27 & 47.2 & 17 & 33.3 & 12 & 19.4 & 7 & 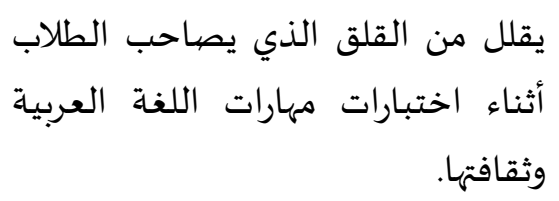 & 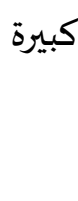 \\
\hline 2 & 2.50 & 58.1 & 21 & 33.3 & 12 & 8.3 & 3 & 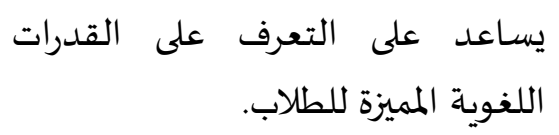 & جبيرة \\
\hline 2 & 2.41 & 47.2 & 17 & 47.2 & 17 & 5.6 & 2 & يساعد على تنمية العناصر اللغوية لدى & 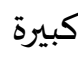 \\
\hline
\end{tabular}




\section{ILA الجمعية المصرية للقر اءة والمعرفة عضو الجمعية الدولية للمعرفة}

\begin{tabular}{|c|c|c|c|c|c|c|c|c|c|}
\hline & & & & & & & & الطلاب. & جدا \\
\hline 2 & 2.25 & 41.7 & 15 & 41.7 & 15 & 16.7 & 6 & يساعد على تنمية مهارة الاستماع لدى & كبيرة \\
\hline 2 & 2.19 & 38.9 & 14 & 41.7 & 15 & 19.4 & 7 & الطابلاب. على تنمية مهارة الكلام لدى & كبيرة \\
\hline 2 & 2.58 & 63.9 & 23 & 30.6 & 11 & 5.6 & 2 & الطاعلد على تنمية مهارة القراءة لدى & كبيرة \\
\hline 2 & 2.55 & 63.9 & 23 & 27.8 & 10 & 8.3 & 3 & الطاعلد على تنمية مهارة الكتابة لدى & جبيرة \\
\hline 2 & 2.53 & 54.3 & 366 & 34.4 & 232 & 11.3 & 76 & الاتجاه العام للمحكمين نحو التعرف اهمية استخدام ملف الانجـاز. & كبيرة \\
\hline
\end{tabular}

الجـدول أعلاه يبين للباحث التكرارات والنسب المئوية والمتوسطات للمحور

الأول (أهمية استخدام معلمي اللغة العربية للناطقين بغيرها ملف الإنجاز في تقويم

الأداء اللغوي) حيث كانت قيمة أعلى متوسط لكل عبارات هذا المحور هي (ع.ب) للعبارة (ينمي القدرة على التعلم الذاتي) كان اتجاهها كبيرة جدا؛ ويستنتج الباحث من كل هذا أن جميع عبارات هذا المحور من ناحية أهمية ملف الانجاز كانت في إطار كبيرة وكبيرة جدا.

والمتوسط العام لكل عبارات المحور نجد أن قيمتاه كانت (r.Or) أي أن الاتجاه العام للمحكمين نحو التعرف على أهمية استخدام ملف الانجاز للمحكمين كانت أهميته كبيرة جدا. وعند مقارنة هذا المتوسط مع متوسط مقياس ليكرت لثلاثي الذي كانت قيمتاه (Y) الذي يأخذ اتجاه المحايدة نجده أكبر من قيمة متوسط مقياس ليكرت، وهذا يثبت للباحث أن الاتجاه العام للمحكمين نحو التعرف على أهمية استخدام ملف الانجاز كان إيجابيا. 


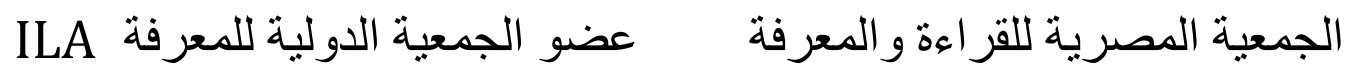

الإجابة عن السؤال الثاني:

والجدول التالي يجيب عن السؤال الثاني الذي نصها: "ما مدى استخدام معلمي

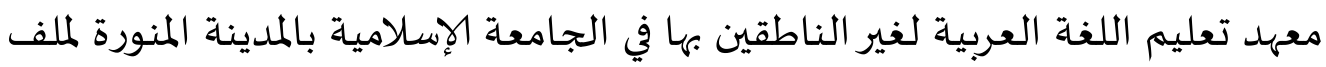

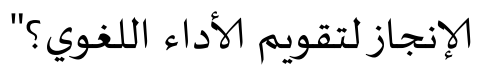

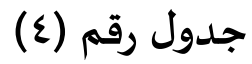

يوضح التكرارات والنسب المئوية والمتوسط العام للبيانات ومتوسط مقياس ليكرت

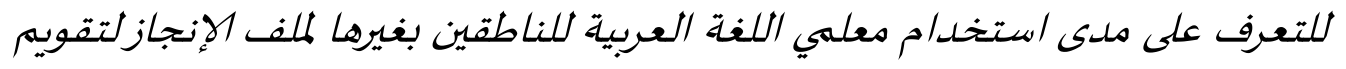

الوداء اللغوي.

\begin{tabular}{|c|c|c|c|c|c|c|c|c|c|c|c|c|c|}
\hline \multirow{2}{*}{ 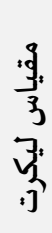 } & \multirow{2}{*}{ 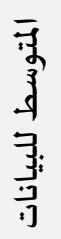 } & \multicolumn{2}{|c|}{ كبيرة جدا } & \multicolumn{2}{|c|}{ كبيرة } & \multicolumn{2}{|c|}{ متوسطة } & \multicolumn{2}{|c|}{ ضعيفة } & \multicolumn{2}{|c|}{ منعدمة } & \multirow[t]{2}{*}{ العبـارة } & \multirow[b]{2}{*}{ 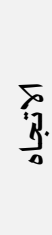 } \\
\hline & & . & $\frac{\overline{3}}{\sqrt[3]{3}}$ & . & $\frac{\overline{3}}{\sqrt[3]{3}}$ & . & $\frac{\overline{3}}{\sqrt[3]{3}}$ & . & $\frac{\overline{3}}{3}$ & . & $\frac{\overline{3}}{3}$ & & \\
\hline 3 & $\begin{array}{r}2.7 \\
5\end{array}$ & 16.7 & 6 & 16.7 & 6 & 16.7 & 6 & 25.0 & 9 & 25.0 & 9 & لمال الساعد البلاب & $\overbrace{3}^{3}$ \\
\hline
\end{tabular}


ILA الجمعية المصرية للقر اعة والمعرفة عضو الجمعية الدولية للمعرفة

\begin{tabular}{|c|c|c|c|c|c|c|c|c|c|c|c|c|c|}
\hline 3 & $\begin{array}{c}2.8 \\
0\end{array}$ & 22.2 & 8 & 13.9 & 5 & 13.9 & 5 & 22.2 & 8 & 27.8 & 10 & 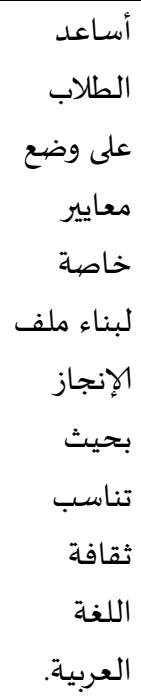 & 多 \\
\hline 3 & $\begin{array}{c}2.7 \\
7\end{array}$ & 22.2 & 8 & 16.7 & 6 & 13.9 & 5 & 11.4 & 4 & 36.3 & 13 & أطلب من & $\frac{3}{3}$ \\
\hline 3 & $\begin{array}{c}3.0 \\
0\end{array}$ & 22.2 & 8 & 27.8 & 10 & 8.3 & 3 & 11.1 & 4 & 30.6 & 11 & أهداف أحدد الهداف & $\frac{3}{3}$ \\
\hline
\end{tabular}


الجمعية المصرية للقر اءة والمعرفة عضو الجمعية الدولية للمعرفة ILA

\begin{tabular}{|c|c|c|c|c|c|c|c|c|c|c|c|c|c|}
\hline 3 & $\begin{array}{c}3.0 \\
0\end{array}$ & 25.0 & 9 & 11.1 & 4 & 27.8 & 10 & 11.1 & 4 & 25.0 & 9 & 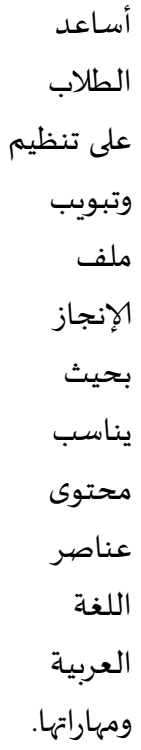 & $\frac{3}{3}$ \\
\hline 3 & $\begin{array}{c}2.9 \\
1\end{array}$ & 22.2 & 8 & 22.2 & 8 & 11.1 & 4 & 13.9 & 5 & 30.6 & 11 & 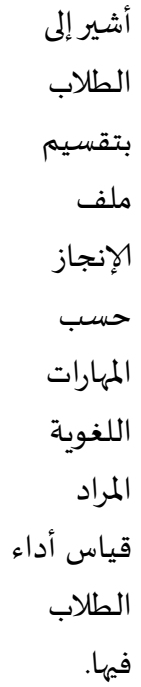 & $\frac{3}{3}$ \\
\hline
\end{tabular}


ILA الجمعية المصرية للقر اءة و المعرفة عضو الجمعية الدولية للمعرفة

\begin{tabular}{|c|c|c|c|c|c|c|c|c|c|c|c|c|c|}
\hline 3 & $\begin{array}{c}2.9 \\
7\end{array}$ & 22.2 & 8 & 16.7 & 6 & 22.2 & 8 & 13.9 & 5 & 25.0 & 9 & ملف ملف ملى مجمول & $\frac{3}{3}$ \\
\hline 3 & $\begin{array}{c}2.8 \\
8\end{array}$ & 19.4 & 7 & 19.4 & 7 & 19.4 & 7 & 13.9 & 5 & 27.8 & 10 & 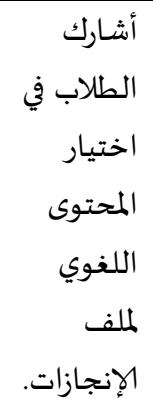 & $\frac{3}{3}$ \\
\hline 3 & $\begin{array}{c}2.9 \\
4\end{array}$ & 25.0 & 9 & 16.7 & 6 & 11.1 & 4 & 22.2 & 8 & 25.0 & 9 & للطاب & $\frac{3}{3}$ \\
\hline
\end{tabular}




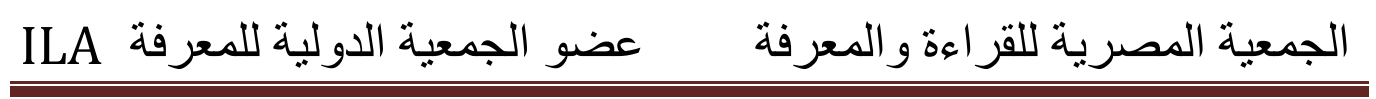

\begin{tabular}{|c|c|c|c|c|c|c|c|c|c|c|c|c|c|}
\hline 3 & $\begin{array}{c}2.9 \\
7\end{array}$ & 22.2 & 8 & 19.4 & 7 & 16.7 & 6 & 16.7 & 6 & 25.0 & 9 & 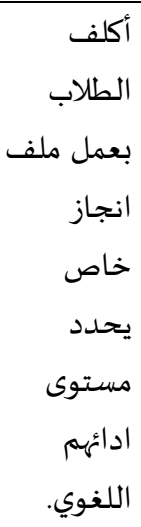 & $\frac{3}{3}$ \\
\hline 3 & $\begin{array}{c}3.0 \\
5\end{array}$ & 27.8 & 10 & 16.9 & 6 & 13.9 & 5 & 16.7 & 6 & 25.0 & 9 & مل ملف الشفرف على & $\frac{3}{3}$ \\
\hline 3 & $\begin{array}{c}2.9 \\
4\end{array}$ & 22.2 & 8 & 16.7 & 6 & 19.4 & 7 & 16.7 & 6 & 25.0 & 9 & 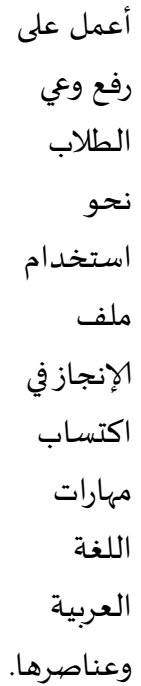 & $\frac{3}{3}$ \\
\hline
\end{tabular}




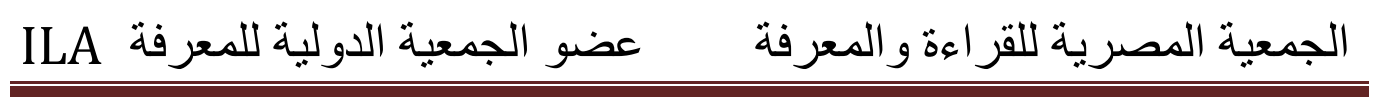

\begin{tabular}{|c|c|c|c|c|c|c|c|c|c|c|c|c|c|}
\hline 3 & $\begin{array}{c}2.8 \\
3\end{array}$ & 19.4 & 7 & 13.9 & 5 & 25.0 & 9 & 13.7 & 5 & 27.8 & 10 & الأؤكد على الإخراج & $\frac{3}{3}$ \\
\hline 3 & $\begin{array}{c}3.0 \\
8\end{array}$ & 22.2 & 8 & 25.0 & 9 & 16.7 & 6 & 11.1 & 4 & 25.0 & 9 & 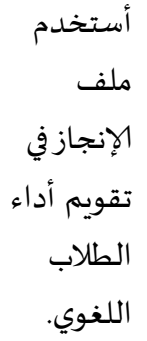 & $\frac{3}{3}$ \\
\hline 3 & $\begin{array}{c}3.1 \\
3\end{array}$ & 19.4 & 7 & 30.6 & 11 & 16.7 & 6 & 11.1 & 4 & 22.2 & 8 & مل درجات & $\frac{3}{3}$ \\
\hline 3 & $\begin{array}{c}2.8 \\
6\end{array}$ & 19.4 & 7 & 22.2 & 8 & 11.1 & 4 & 19.4 & 7 & 27.8 & 10 & 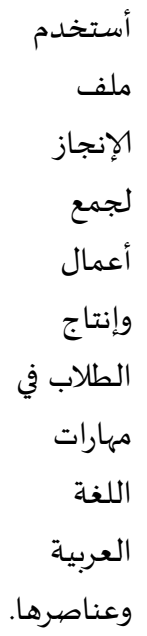 & $\frac{3}{3}$ \\
\hline
\end{tabular}


الجمعية المصرية للقر اءة والمعرفة عضو الجمعية الدولية للمعرفة ILA

\begin{tabular}{|c|c|c|c|c|c|c|c|c|c|c|c|c|c|}
\hline 3 & $\begin{array}{c}2.6 \\
9\end{array}$ & 19.4 & 7 & 16.7 & 6 & 11.1 & 4 & 19.4 & 7 & 33.3 & 12 & 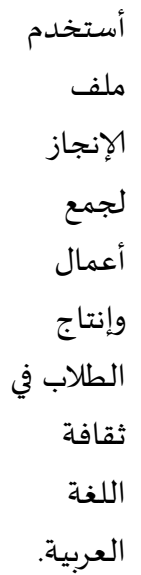 & $\frac{3}{3}$ \\
\hline 3 & $\begin{array}{c}2.9 \\
4\end{array}$ & 22.2 & 8 & 19.4 & 7 & 13.9 & 5 & 19.4 & 7 & 25.0 & 9 & 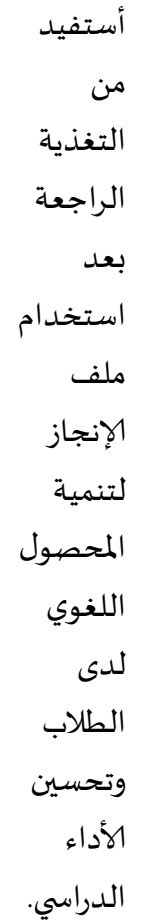 & $\frac{3}{3}$ \\
\hline
\end{tabular}




\section{ILA الجمعية المصرية للقر اءة والمعرفة عضو الجمعية الدولية للمعرفة}

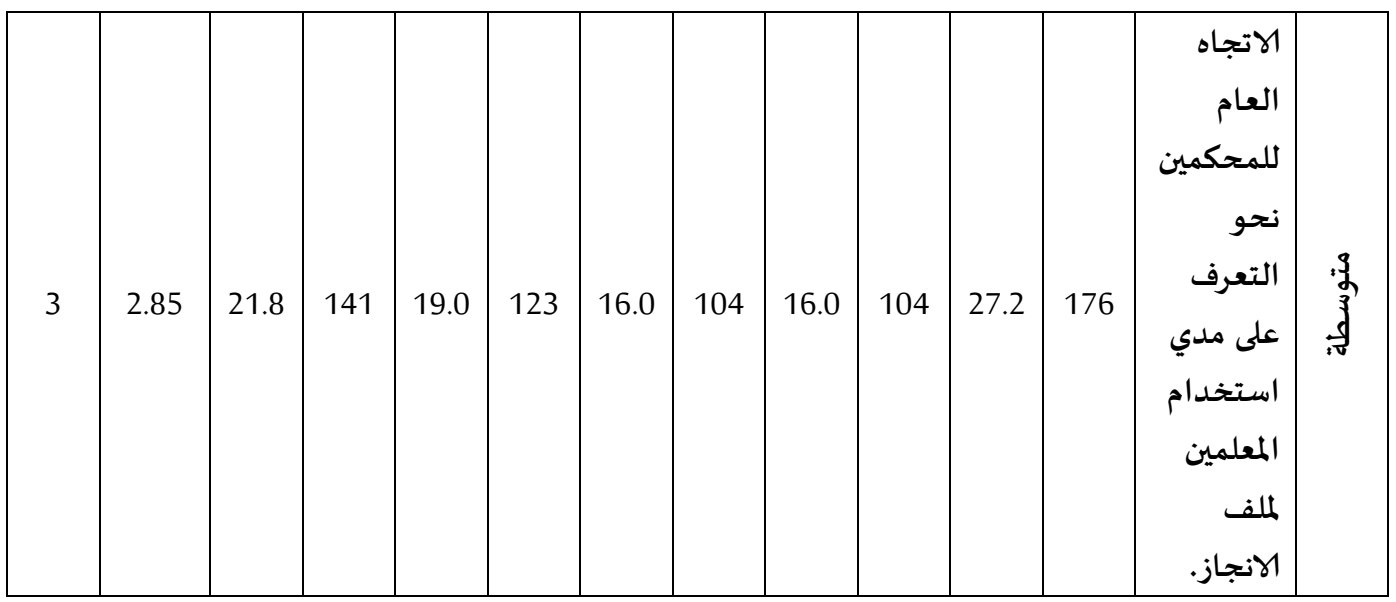

الجدول أعلاه يبين للباحث التكرارات والنسب المئوية والمتوسطات للمحور

الثاني (ما مدى استخدام معلمي اللغة العربية للناطقين بغيرها لملف الإنجاز لتقويم الأداء اللغوي) حيث كانت قيمة أعلى متوسط لكل عبارات هذا المحور هي (....ب) للعبارتين (أحدد أهداف استخدام ملف الإنجاز في تقويم الأداء اللغوي للطلاب قبل استخدامه، أسـاعد الطلاب على تنظيم وتبويب ملف الإنجاز بحيث يناسب محتوى عناصر اللغة العربية ومهاراتها) حيث كان اتجاههما متوسطة أي أن المحكمين يستخدمون ملف الانجاز لتقويم الأداء اللغوي، وأنهم يقوّمون الأداء اللغوي قبل

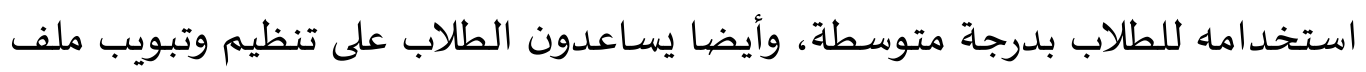
الإنجاز بحيث يناسب محتوى عناصر اللغة العربية، ومهاراتها بلدرجة متوسطة، وقيمة

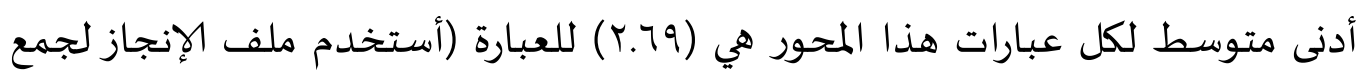
أعمال وإنتاج الطلاب في ثقافة اللغة العربية)، وكان اتجاهها متوسطة. ويستنتج الباحث من كل هذا أن جميع عبارات هذا المحور من ناحية مدى استخدام معلمي اللغة العربية

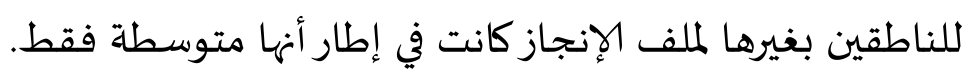
والمتوسط العام لكل عبارات المحور نجد أن قيمتاه كانت (10.ب) أي أن الاتجاه العام للمحكمين نحو التعرف على مدي استخدام المعلمين لملف الانجاز كانت أهميتـا متوسطة وعند مقارنة هذا المتوسط مع متوسط مقياس ليكرت الخماسي الذي كانت 


\section{ILA الجمعية المصرية للقر اءة والمعرفة عضو الجمعية الدولية للمعرفة}

قيمتا (ץ) الذي يأخذ اتجاه المحايدة نجده يكاد يساوي قيمة متوسط مقياس ليكرت؛

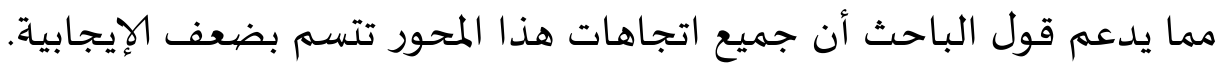
الإجابة عن السؤال الثالث:

الجدول التالي يجيب عن السؤال الثالث الذي نصها: "ما المعوقات التي تحول دون استخدام معلمي معهد تعليم اللغة العربية للناطقين بغيرها بالجامعة الإسلامية البهاية

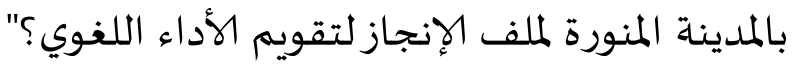

\section{جدول رقم (0)}

يوضح التكرارات والنسب المئوية والمتوسط العام للبيانات ومتوسط مقياس ليكرت للتعرف على المعوقات التي تحول دون استخدام معلمي معهلد تعليم اللغة العبرية بالجامعة الإسلامية بالملدينة المنورة لملف الإنجازلتقويم الأداء اللغوي.

\begin{tabular}{|c|c|c|c|c|c|c|c|c|c|c|c|c|c|}
\hline \multirow{2}{*}{ 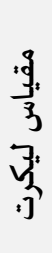 } & \multirow{2}{*}{ 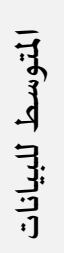 } & \multicolumn{2}{|c|}{ كبيرة جدا } & \multicolumn{2}{|c|}{ كبيرة } & \multicolumn{2}{|c|}{ متوسطة } & \multicolumn{2}{|c|}{ قليلة } & \multicolumn{2}{|c|}{ لا تمثلة } & \multirow[t]{2}{*}{ العبـارة } & \multirow{2}{*}{ 隽 } \\
\hline & & . & 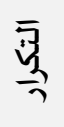 & . & 哥 & . & 哥 & 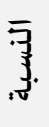 & 雾 & . & 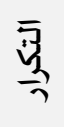 & & \\
\hline 3 & $\begin{array}{c}3.6 \\
9\end{array}$ & 40.7 & 15 & 19.4 & 7 & 19.4 & 7 & 5.6 & 2 & 13.9 & 5 & | لطلة & 巽: \\
\hline
\end{tabular}


ILA الجمعية المصرية للقر اعة والمعرفة عضو الجمعية الدولية للمعرفة

\begin{tabular}{|c|c|c|c|c|c|c|c|c|c|c|c|c|c|}
\hline 3 & $\begin{array}{c}3.9 \\
4\end{array}$ & $\begin{array}{c}47.1 \\
2\end{array}$ & 17 & 19.4 & 7 & 19.4 & 7 & 8.3 & 3 & 5.6 & 2 & الألمباء & 离: \\
\hline 3 & $\begin{array}{c}3.8 \\
3\end{array}$ & 41.7 & 15 & 19.4 & 7 & 27.8 & 10 & 2.8 & 1 & 8.3 & 3 & 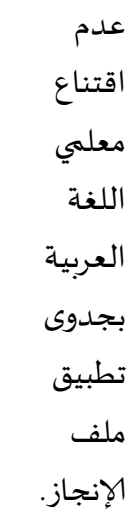 & 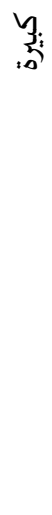 \\
\hline 3 & $\begin{array}{c}4.0 \\
0\end{array}$ & 47.2 & 17 & 25.0 & 9 & 13.9 & 5 & 8.3 & 3 & 5.6 & 2 & كثرة & 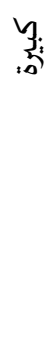 \\
\hline 3 & $\begin{array}{c}4.4 \\
3\end{array}$ & 63.9 & 23 & 27.8 & 10 & 19.4 & 7 & 2.8 & 1 & 2.8 & 1 & ملد & 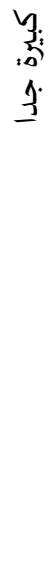 \\
\hline
\end{tabular}


ILA الجمعية المصرية للقر اعة والمعرفة عضو الجمعية الدولية للمعرفة

\begin{tabular}{|c|c|c|c|c|c|c|c|c|c|c|c|c|c|}
\hline 3 & $\begin{array}{c}4.0 \\
0\end{array}$ & 44.4 & 16 & 30.6 & 11 & 13.9 & 5 & 2.8 & 1 & 8.3 & 3 & الراء & 离: \\
\hline 3 & $\begin{array}{c}3.6 \\
6\end{array}$ & 36.1 & 13 & 25.0 & 9 & 16.7 & 6 & 13.9 & 5 & 8.4 & 3 & 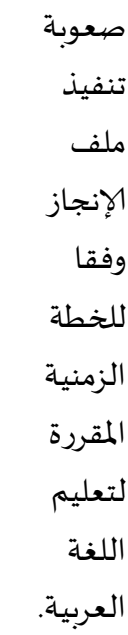 & 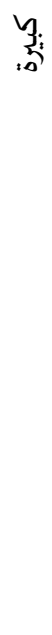 \\
\hline 3 & $\begin{array}{c}4.3 \\
3\end{array}$ & 47.2 & 17 & 22.2 & 8 & 5.6 & 2 & 0.0 & 0 & 8.3 & 3 & أعثرة & $\begin{array}{c}1 \\
1 \\
1 \\
1\end{array}$ \\
\hline 3 & $\begin{array}{c}3.8 \\
0\end{array}$ & 33.3 & 12 & 30.6 & 11 & 27.8 & 10 & 0.0 & 0 & 8.3 & 3 & تقدير زمن & 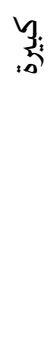 \\
\hline
\end{tabular}




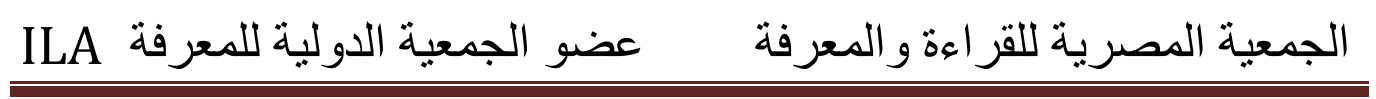

\begin{tabular}{|c|c|c|c|c|c|c|c|c|c|c|c|c|c|}
\hline 3 & $\begin{array}{c}3.5 \\
0\end{array}$ & 33.3 & 12 & 25.0 & 9 & 27.8 & 10 & 2.8 & 1 & 16.7 & 6 & مل ملاسبة & 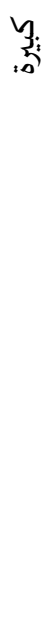 \\
\hline 3 & $\begin{array}{c}3.4 \\
4\end{array}$ & 27.8 & 10 & 27.8 & 10 & 13.9 & 5 & 5.6 & 2 & 19.4 & 7 & لمداية & 幽: \\
\hline 3 & 3.6 & 42.2 & 167 & 24.7 & 98 & 18.7 & 74 & 4.8 & 19 & 9.6 & 38 & مل ملم العام & 岕 \\
\hline
\end{tabular}

الجدول أعلاه يبين للباحث التكرارات والنسب المئوية والمتوسطات للمحور 纟ᄉ 


\section{ILA الجمعية المصرية للقر اءة والمعرفة عضو الجمعية الدولية للمعرفة}

الثالث (المعوقات التي تحول دون استخدام معلمي معهد تعليم اللغة العربية بالجامعة الإسلامية بالمدينة المنورة لملف الإنجاز لتقويم الأداء اللغوي) حيث كانت قيمة أعلى متوسط لكل عبارات هذا المحور هي (4.44) للعبارة. (عدم تدريب معلم اللغة

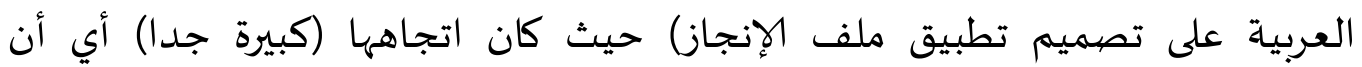
المحكمين يواجهون مشكلة عدم تدريب معلم اللغة العربية على تصميم تطبيق ملف الإنجاز بدرجة كبيرة جدا وقيمة أدنى متوسط لكل عبارات هذا المحور هي (عـ.ب)

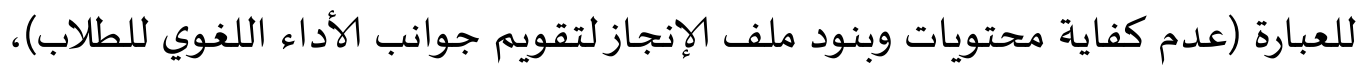

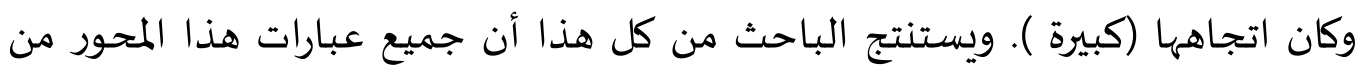
ناحية المعوقات التي تحول دون استخدام معلمي معهد تعليم اللغة العربية لملف الإنجاز لتقويم الأداء اللغوي كانت في إطار أنها كبيرة وكبيرة جدا.

والمتوسط العام لكل عبارات المحور نجد أن قيمتاه كانت (ج.ب) أي أن الاتجاه العام للمحكمين نحو التعرف على معوقات ملف الانجاز تعوقه مشاكل بدرجة كبيرة وعند مقارنة هذا المتوسط مع متوسط مقياس ليكرت الخماسي الذي كانت قيمته (r)

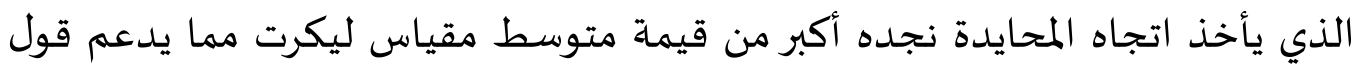

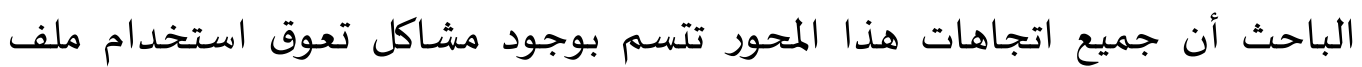
الانجاز بمعهد تعليم اللغة العربية بالجامعة الإسلامية بالمدينة المنورة. وفيما يلي الجدول يوضح المتوسط الحسابي والانحراف المعياري للمحاور الرئيسة 


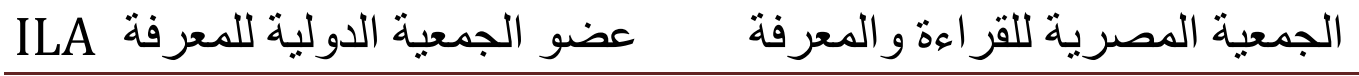

جدول رقم (7) - (7) - (ج)

يوضح الؤساط المرجحة والانحرافات المعيارية للمحاور الرئيسة في الاستبانة:

\begin{tabular}{|c|c|c|c|}
\hline المعياري & المتسابي & العدد & المححاور الرئيسة للاستبانة \\
\hline .584 & 2.52 & 36 & أهمية استخدام ملف الانجاز \\
\hline 1.27 & 3.12 & 36 & الاتجاه العام لمعوقات واستخدام ملف الإنجاز \\
\hline 1.22 & 3.59 & 36 & المإنجاز الموقات التي تحول دون استخدام المعلمين لملف \\
\hline 1.40 & 2.84 & 36 & مدى استخدام المعلمين لملف الانجاز \\
\hline
\end{tabular}

الجدول أعلاه يبين لنا حجم العينة والمتوسطات الحسابية المرجحة

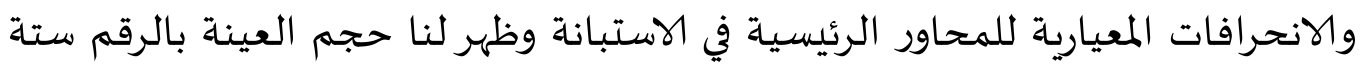
وثلاثين لكافة العبارات مما يدل على عدم وجود قيم مفقودة للعبارات.

وتظهر لنا قيم المتوسطات الحسابية المرجحة والتي كانت قيمة أقل متوسط أماندا

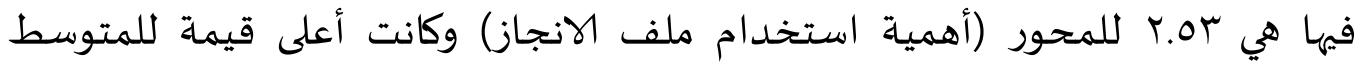

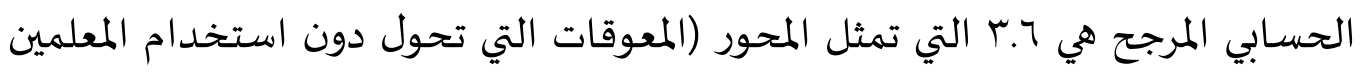

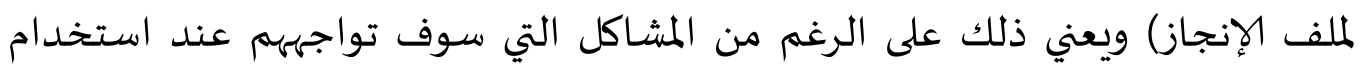
ملف الانجاز إلا أههم على وعي تام بأهمية استخدام ملف الأن الانجاز. وأيضا تظهر لنا قيم الانحراف المعياري وكانت أقل قيمة له هي

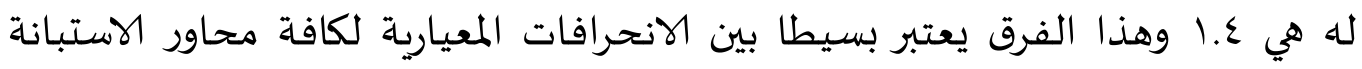
الرئيسية مما يمكن القول إن الإجابات على كافة المحاور كانت ايجابية. 


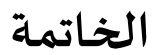

تناول البحث أهمية استخدام ملف الإنجاز لدى معلمي اللغة العربية في معهد العيد

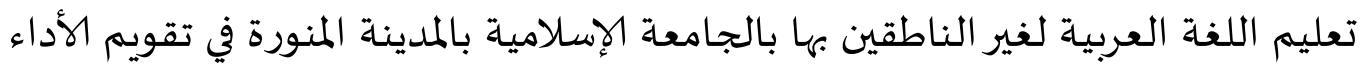

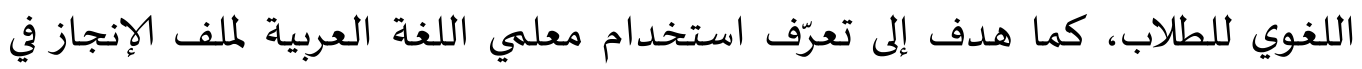

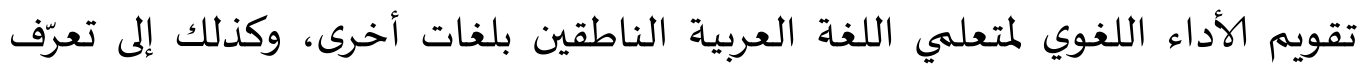

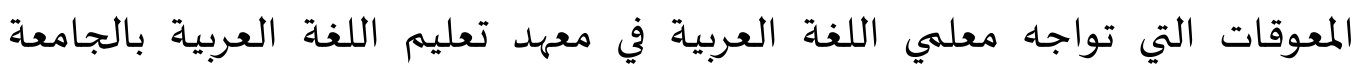
الإسلامية بالمدينة المنورة لاستخدام ملف الإنجاز تقويم الأداء اللغوي.

وتوصل البحث إلى عدة نتائج، وعلى ضوء هذه النتائج خلص إلى عدة توصيات

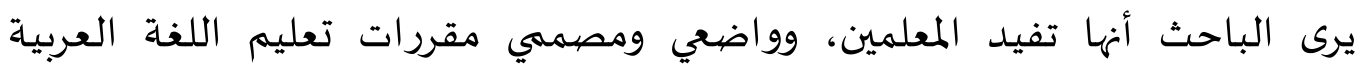

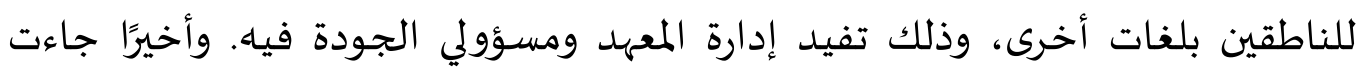
المقترحات على ضوء توصيات البحث مكملة له.

\section{نتائج البحث وتفسيرها}

1. معظم عبارات محور أهمية استخدام معلمي اللغة العربية بالجامعة الإسلامية بالمدينة المنورة ملف الإنجاز في تقويم الأداء اللغوي كانت بين كبيرة وكبيرة جدات التها، وهذا يدل على أهمية ملف الإنجاز في التقويم اللغوي.

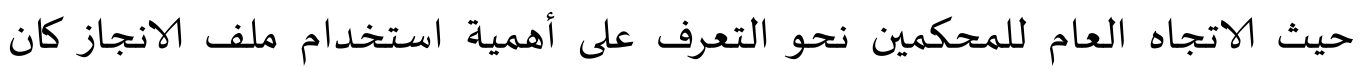

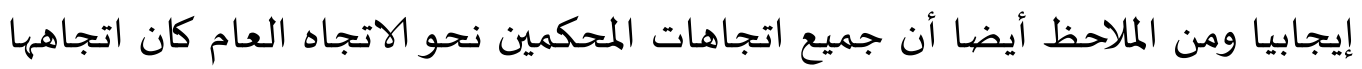

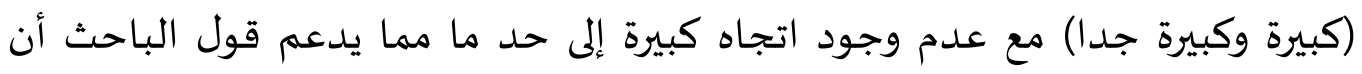

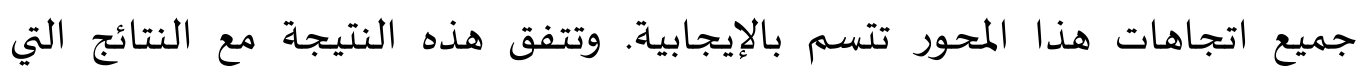

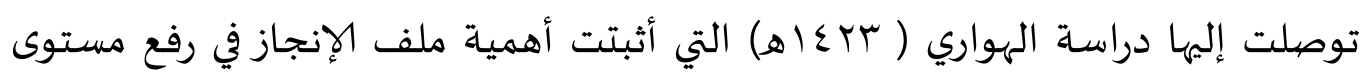

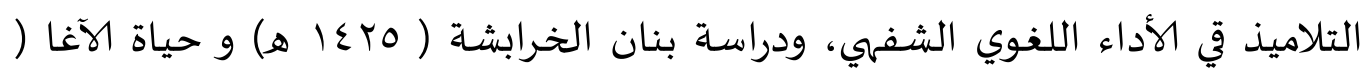

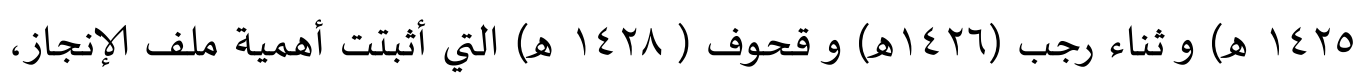

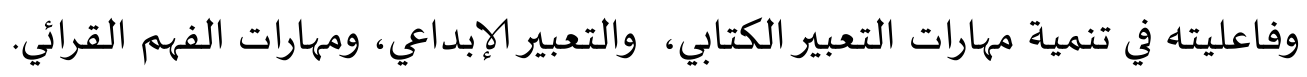




\section{الجمعية المصرية للقر اعة والمعرفة عضو الجمعية الدولية للمعرفة المي}

r. جميع عبارات محور ما مدى استخدام معلمي معهد تعليم اللغة العربية لغير

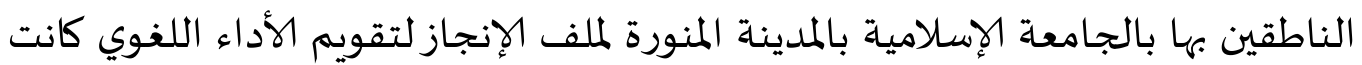

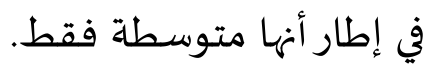

والمتوسط العام لكل عبارات المحور نجد أن قيمتاه كانت (ب0.^) أي أن الاتجاه العام

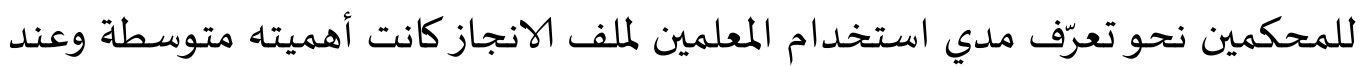
مقارنة هذا المتوسط مع متوسط مقياس ليكرت الخماسي الذي كانت قيمته (ب) والذي

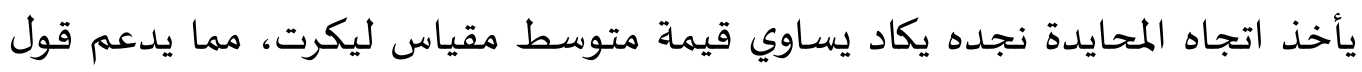

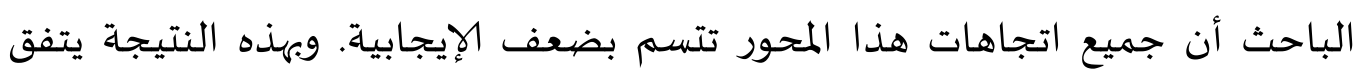

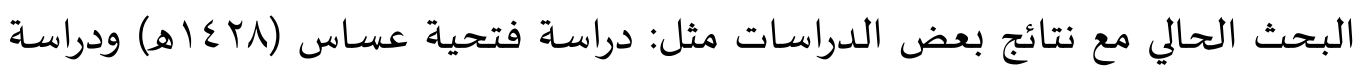
فلمبان (ابـعا هـ) التي أشارت إلى ضعف استخدام ملف الإنجاز في عملية التقويم. r. جميع عبارات محور المعوقات التي تحول دون استخدام معلمي معهد تعليم اللغة

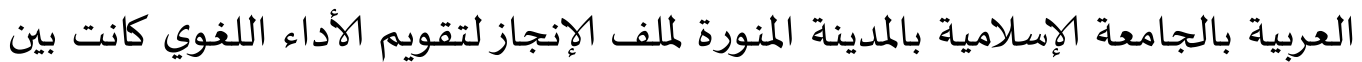
كبيرة وكبيرة جدا.

والمتوسط العام لكل عبارات المحور نجد أن قيمتاه كانت (T.Y) أي أن الاتجاه العام للمحكمين نحو تعرّف معوقات ملف الانجاز تعوقه مشاكل بدرجة كبيرة وعند مقارنة هذا المتوسط مع متوسط مقياس ليكرت الخماسي الذي كانت قيمته (ب) والذي يأخذ

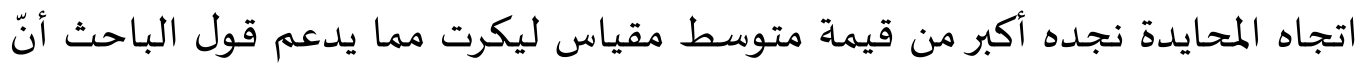
جميع اتجاهات هذا المحور تتسم بوجود مشاكل تعوق استخدام ملف الانجاز بمعهد تعليم اللغة العربية بالجامعة الإسلامية بالمدينة المنورة. وتتفق هذه النتيجة مع النتائج

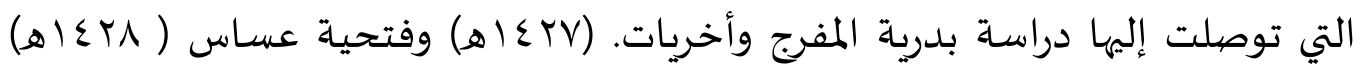

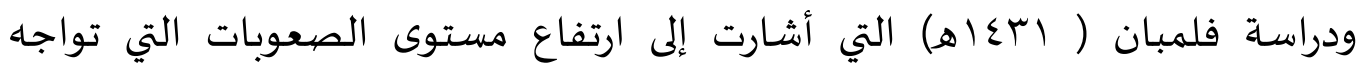
المعلمات في استخدام ملف الإنجاز في عملية التقويم. 


\section{ILA الجمعية المصرية للقر اءة والمعرفة عضو الجمعية الدولية للمعرفة}

\section{التوصيات}

في ضوء النتائج البحث السابقة يمكن تقديم التوصيات الآتية:

ا. ربط أهداف ومحتوى مقررات عناصر اللغة العببية ومهاراتها للناطقين بغيرها بما يحقق جودة استخدام ملف الإنجاز لتقويم الأداء اللغوي للطلاب. r. اعتماد ملف الإنجاز في تقويم الأداء اللغوي لطلاب معهد تعليم اللغة العربية بالجامعة الإسلامية بالمدينة المنورة.

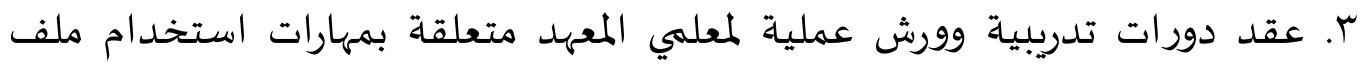
الإنجاز في تقويم الأداء اللغوي لطلاب معهد تعليم اللغة العربية بالجامعة الإسلامية

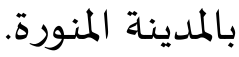

ع. وضع معايير واضحة وعلمية لكيفية تقويم ملف الإنجاز لتقويم الأداء اللغوي للطلاب.

0. إصدار دليل علمي إرشادي يتضمن كيفية استخدام ملف الإنجاز لتقويم الأداء

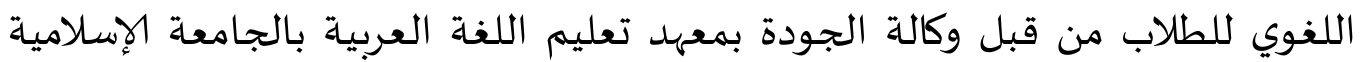

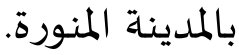
المقترحات

في ضوء النتائج والتوصيات السابقة يقترح الباحث إجراء الدراسات الآتية: 1. فاعلية استخدام ملف الإنجاز في تنمية عناصر اللغة العربية ومهاراتها لدى طلاب معهد تعليم اللغة العربية بالجامعة الإسلامية بالمدينة المنورة. r. فاعلية استخدام ملف الإنجاز في تنمية الثقافة الإسلامية لدى طلاب معهد تعليم اللغة العربية بالجامعة الإسلامية بالمدينة المنورة. 


\section{الجمعية المصرية للقر اعة والمعرفة عضو الجمعية الدولية للمعرفة المي}

r. برنامج تدريبي متميز لمعلمي معهد تعليم اللغة العربية بالجامعة الإسلامية بالمدينة

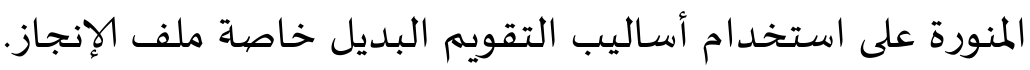

\section{المراجع العربية}

الآغا، حياة زكريا (0بـ إه). استخدام ملفات الإنجاز والتعلم التعاوني في تنمية مهرات التعبير الابداعي لدى طالبات الصف العاشر بفلسطين. رسالة دكتوراه غير مإداه

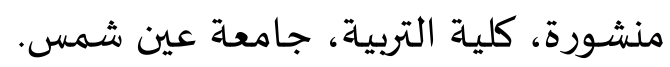

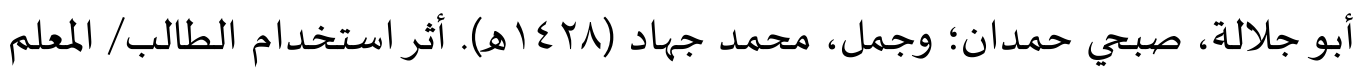

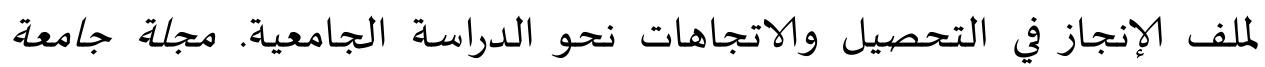

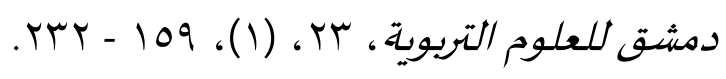

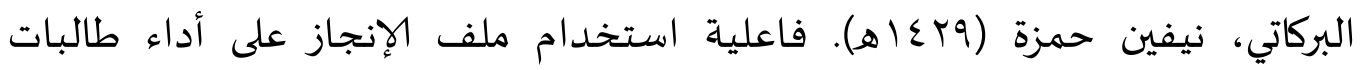
الرياضيات بمقرر النشاط في برنامج الإعداد التربوي بجامع أم القرى. مجلة

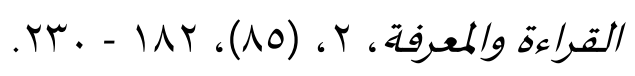

جابر، جابر عبد الحميد (ךrعا هـ). اتجاهات وتجارب معاصرة في تقويم أداء التلميذ والمدرس. القاهرة: دار الفكر.

حسين، عادل (1) (ه)). فعالية برنامج تدريبي في استخدام ملف إنجاز الطالب

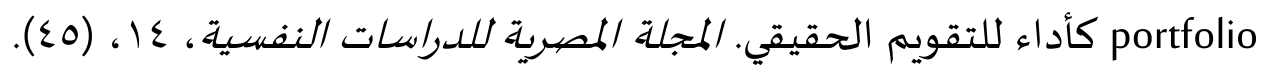
خليل، محمد أبو الفتوح (بrع اهـ). أثر استخدام ملف أعمال الطالب كأداء للتقويم تحما

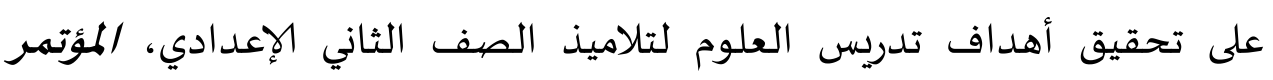
العلمي الرابع عشر: مناهج التعليم في ضيوء مضهوم الوداء، القاهرة. تلفئ.

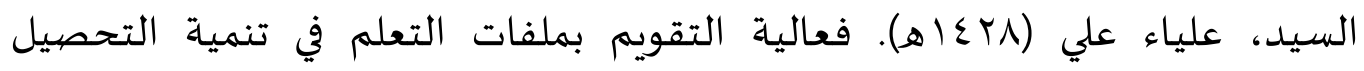
والتفكير الابتكاري وخفض قلق الامتحان في مادة العلوم لدى تلاميذ المرحلة

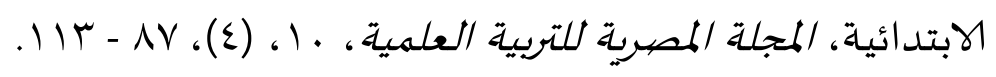




\section{الجمعية المصرية للقر اعة والمعرفة عضو الجمعية الدولية للمعرفة}

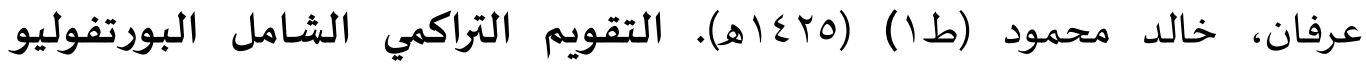
ومعوقات استخدامه في مدارسنا. القاهرة: عالم الكتب.

علام، صلاح الدين (.rعاهـ). التقويم التربوي البديل: أسسه النظرية والمنهجية وتطبيقاته الميدانية. القاهرة: دار الفكر العربي. عيد، غادة خالد (ط ا) (FVV) (ه). القياس والتقويم التربوي مع تطبيقات برنامج

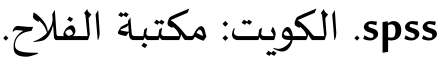
فلمبان، آذار، (آسعا ه). واقع استخدام معلمات اللغة العربية ملف الإنجاز في تقويم العيم

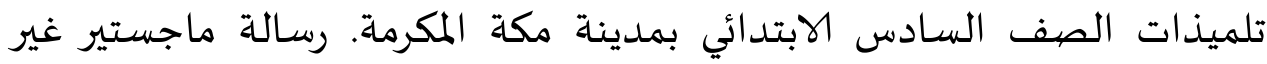
منشورة، كلية التربية، جامعة أم القرى.

قحوف، أكرم إبراهيم (1) (اه). أثر الأنشطة اللغوية المرتبطة بملفات الإنجاز

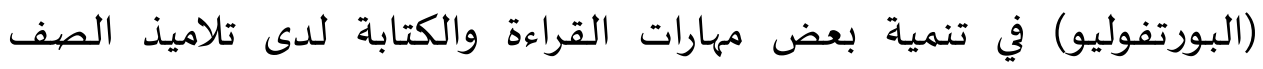

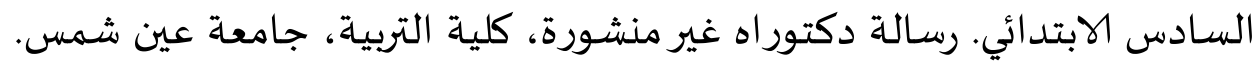
اللقاني، أحمد حسين؛ والجمل، علي أحمد (ط ا) (ع أl(ه). معجم المصطلحات التربوية المعرفة في المناهج وطرق التدريس. عمان: دار المسيرة. مراد، خلود (Yr \& (ه). أساليب التقويم لدى معلمي ومعلمات الحلقة الأولى من التعليم

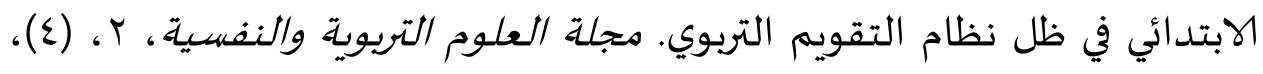
$.194-194$

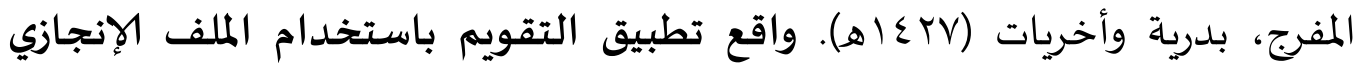

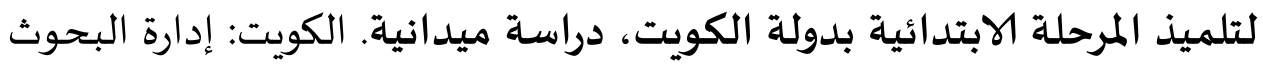
والتطوير التربوي. 


\section{الجمعية المصرية للقراعة والمعرفة عضو الجمعية الدولية للمعرفة ILA}

الهواري، خالد محمود (بr أه). أثر التفاعل بين طريقة التعليم ونمط الاختبار على مستوى الأداء اللغوي الشفهي لدى تلاميذ الصف الخامس الابتدائي. رسالة دكتوراه غير منشورة، كلية التربية، جامعة الأزهر.

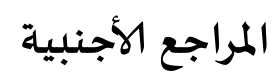

Chen, Yuh- Mei. (2006) EFL Instruction and assessment with portfolios: A Case study in Taiwan. The Asian EFL Journal, 8, (1), 69-96. 